A C G

publications

Org. Commun. 14:3 (2021) 255-269

organic

communications

\title{
Synthesis, antioxidant and carbonic anhydrase inhibitory properties of monopeptide-anthraquinone conjugates
}

\section{Hasan Küçükbay $\oplus^{* 1}$, F. Müzeyyen Parladı ${ }^{1}$, F. Zehra Küçükbay $\oplus^{2}$, Andrea Angeli ${ }^{3}$ Gianluca Bartolucci $\left({ }^{3}{ }^{3}\right.$ and Claudiu T. Supuran ()$^{*}$}

\author{
${ }^{1}$ Department of Chemistry, Faculty of Science, İnönü University, Malatya 44280, Türkiye \\ ${ }^{2}$ Department of Basic Pharmaceutical Sciences, Faculty of Pharmacy, Inönü University, 44280 \\ Malatya, Türkiye \\ ${ }^{3}$ Dipartimento Neurofarba, Sezione Di Scienze Farmaceutiche E Nutraceutiche e Laboratorio Di \\ Chimica
}

Bioinorganica, Universita`Degli Studi Di Firenze, Sesto Fiorentino, Florence, Italy

(Received July 06, 2021; Revised July 26, 2021; Accepted August 10, 2021)

\begin{abstract}
Novel monopeptide-anthraquinone conjugates (1-16) were synthesized by the reaction of appropriate $\mathrm{N}$-protected amino acid with 2-hydroxymethylanthraquinone in good or high yields. The structural elucidation of the new compounds was accomplished by ${ }^{1} \mathrm{H}$ NMR, ${ }^{13} \mathrm{C}$ NMR, MS, FT-IR spectroscopy and elemental analysis techniques. The carbonic anhydrase (CA, EC 4.2.1.1) inhibitory activity of the new compounds was determined against two human (h) isoforms, hCA I and hCA II. While three of the sixteen compounds showed moderate in vitro carbonic anhydrase inhibitory properties against hCA II with inhibition constants in the micromolar level (43.5, 67.4 and $78.1 \mu \mathrm{M}$ ), they did not show inhibitory activity against hCA I up to $100 \mu \mathrm{M}$ concentration. The antioxidant abilities of the compounds were determined using the 1,1-diphenyl-2-picrylhydrazil (DPPH) radical scavenging method, ferric ion reducing assay and metal chelation methods. While a small amount of antioxidant activity was observed according to the DPPH and ferric ion reducing power assay methods, none of the compounds showed antioxidant properties according to the metal chelating activity method at the concentrations studied.
\end{abstract}

Keywords: Anthraquinone derivatives; monopeptide anthraquinone conjugates, carbonic anhydrase inhibition; antioxidant activity. () 2021 ACG Publications. All rights reserved.

\section{Introduction}

Anthraquinone is an anthracene derivative, which is a polynuclear hydrocarbon with three benzene rings linearly fused. Anthraquinone derivatives have been used for about one-third of all organic dye products over the world. ${ }^{1-4}$ They are widely used in different fields such as quantum dots in
*Corresponding
authors:
E-Mail:
hasan.kucukbay@inonu.edu.tr
(K.Kucukbay);
claudiu.supuran@unifi.it (C.T. Supuran)

The article was published by ACG Publications

http://www.acgpubs.org/journal/organic-communications July-September 2021 EISSN:1307-6175

DOI: http://doi.org/10.25135/acg.oc.108.2107.2126

Available online: August 18, 2021 


\section{Monopeptide-anthraquinone conjugates}

semiconducting industry, organic electronic devices applications, ${ }^{5}$ photoelectrocatalysis application, ${ }^{6,7}$ photo oxidant, ${ }^{8}$ organic catalyst, ${ }^{9}$ charge-transfer materials ${ }^{10,11}$ and sensor technology. ${ }^{12,13}$ In addition to their technological importance, anthraquinone derivatives constitute an important class of bioactive compounds for their versatile pharmacological activities such as antimicrobial, ${ }^{14}$ antimalarial, ${ }^{15}$ antioxidant, ${ }^{16}$ anticancer, ${ }^{17,18}$ acetylcholinesterase (AChE), butyrylcholinesterase (BChE), $\beta$-site amyloid precursor protein cleaving enzyme 1 (BACE1) inhibitors, ${ }^{19}$ antiplatelet, ${ }^{20}$ anticoagulant, ${ }^{20}$ antiviral, ${ }^{21}$ anti-Alzheimer's disease ${ }^{22}$ and stimulating topoisomerase II-mediated DNA cleavage. ${ }^{23}$ They $^{2}$ also found in plant-based foods as emodin such as rhubarb, cabbage, beans and buckthorn. ${ }^{24}$

Despite the clinical potential of anthraquinone-amino acid or anthraquninone-peptide conjugates, such conjugates have not been investigated up to now and there are only a few work in the literature. ${ }^{17,25,26}$ Therefore, this study was planned to obtain new possible bioactive compounds inspired by the biological importance of anthraquinones in the literature. ${ }^{27}$ The new monopeptideanthraquinone conjugates in this study were obtained from the reaction of the appropriate $\mathrm{N}$ acylbenzotriazole with 2-hydroxymethyl-antraquinone.

Within the framework of this study, 16 new monopeptide-anthraquinone derivatives were synthesized and hCA I and hCA II enzyme inhibition capacities were evaluated using a stopped flow $\mathrm{CO}_{2}$ hydrase assay. ${ }^{28}$ The antioxidant capacities of the compounds were determined using the DPPH radical scavenging, ferric ions reducing power assay and metal chelating activity methods. ${ }^{29,30,31}$

\section{Experimental}

\subsection{Chemical Material and Apparatus}

The starting materials and reagents used in the reactions were supplied commercially by Aldrich, Acros, Merck, AFG Bioscience, abcr, Bachem, Alfa Aesar or Fluorochem. Nuclear magnetic resonance $\left({ }^{1} \mathrm{H}\right.$ NMR, ${ }^{13} \mathrm{C}$ NMR) spectra were recorded using a Bruker Avance III 400 or $300 \mathrm{MHz}$ spectrometers (Billerica, Massachusetts, USA) in DMSO-d6. Chemical shifts are reported in parts per million (ppm) and the coupling constants $(J)$ are expressed in Hertz $(\mathrm{Hz})$. The assignment of exchangeable protons $\left(\mathrm{OH}\right.$ and $\mathrm{NH}$ ) was confirmed by the addition of $\mathrm{D}_{2} \mathrm{O}$. Positive or negative-ion electrospray ionization (ESI) mass spectra were recorded on a double-focusing Finnigan MAT 95 instrument (Palo Alto, California, USA) with BE geometry. Analytical thin-layer chromatography (TLC) was carried out on Merck silica gel F-254 plates. Infrared spectra were recorded with ATR equipment in the range 4000$650 \mathrm{~cm}^{-1}$ on a Perkin Elmer Spectrum one FTIR spectrophotometer (USA). Elemental analyses were performed with a LECO CHNS-932 elemental analyzer (Michigan, USA). Melting points were recorded using an Electrothermal-9200 melting point apparatus, and are uncorrected. All starting Nprotected monopeptides were prepared according to literature procedures. ${ }^{32-37}$

\subsection{Chemistry}

\subsubsection{General Synthesis Method of Monopeptide-anthraquinone Conjugates (1-15)}

2-Hydroxymethylanthraquinone (1.0 equiv.), 1-(N-protected aminoacyl)benzotriazole (1.0 equiv.) and $\mathrm{E}_{\mathrm{t} 3} \mathrm{~N}$ (1.2 equiv.) were reacted in DMF for 3 hours at room temperature [monitored by TLC, methanol $(5 \%)$ / dichloromethane $(95 \%)$ mixture]. Then, ice water was added into the reaction mixture to precipitate the crude product. The crude product was crystallized from ethanol.

(9,10-Dioxo-9,10-dihydroanthracen-2-yl)methyl ((benzyloxy)carbonyl)glycinate (1): Yellow (82\%); m.p.: $150-151{ }^{\circ} \mathrm{C} ;{ }^{1} \mathrm{H}$ NMR (400 MHz, DMSO- $\left.d_{6}\right): \delta 8.20-8.17(\mathrm{~m}, 4 \mathrm{H}, \mathrm{Ar}-H)$, 7.95-7.87 (m, 3H, Ar$H), 7.82(\mathrm{t}, 1 \mathrm{H}, \mathrm{NH}, J=6.0 \mathrm{~Hz}), 7.37-7.31(\mathrm{~m}, 5 \mathrm{H}, \mathrm{Ar}-H), 5.36\left(\mathrm{~s}, 2 \mathrm{H}, \mathrm{CH}_{2}\right.$-anthraquinone), $5.08(\mathrm{~s}, 2 \mathrm{H}$, $\left.\mathrm{PhCH}_{2} \mathrm{O}\right), 3.94\left(\mathrm{~d}, 2 \mathrm{H}, \mathrm{CONHCH}_{2}, J=4.0 \mathrm{~Hz}\right) .{ }^{13} \mathrm{C} \mathrm{NMR}\left(100 \mathrm{MHz}, \mathrm{DMSO}-d_{6}\right): \delta 182.7(C \mathrm{O}-$ anthraquinone), 182.6 (CO- anthraquinone), $170.6\left(\mathrm{NHCH}_{2} \mathrm{CO}\right), 157.1\left(\mathrm{PhCH}_{2} \mathrm{OCO}\right), 143.2,137.4$, $135.1,135.0,133.7,133.5,133.5,133.4,133.0,128.8,128.3,128.2,127.6,127.2,127.2,126.0$ (Ar-C), $66.1\left(\mathrm{CH}_{2^{-}}\right.$anthraquinone), $65.5\left(\mathrm{PhCH} \mathrm{H}_{2} \mathrm{OCO}\right), 42.8\left(\mathrm{CONHCH}_{2}\right)$. IR $\left(\mathrm{cm}^{-1}\right): v_{(\mathrm{C}=0) e s t e r}: 1748 \mathrm{~cm}^{-1}$,

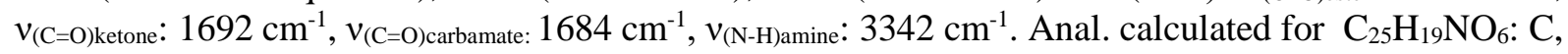
69.92; H, 4.46; N, 3.26. Found: C, 69.10; H, 4.01; N, 3.11. HRMS m/z $\mathrm{C}_{25} \mathrm{H}_{19} \mathrm{NO}_{6}[\mathrm{M}+\mathrm{H}]^{+}$calcd. 430.1, 
Küçükbay et al., Org. Commun. (2021) 14:3 255-269

found 430.1; $\left[\mathrm{M}+\mathrm{NH}_{4}\right]^{+}$calcd. 447.1, found 447.2; $[\mathrm{M}+\mathrm{Na}]^{+}$calcd. 452.0, found 452.1; $[\mathrm{M}+\mathrm{K}]^{+}$calcd. 468.0, found 468.1; [M- $\left.\left(\mathrm{C}_{15} \mathrm{H}_{9} \mathrm{O}_{2}\right)\right]^{+}$calcd. 221.1, found 220.8.

(9,10-dioxo-9,10-dihydroanthracen-2-yl)methyl ((benzyloxy)carbonyl)-L-alaninate (2): Cream (94\%); m.p.: $172-173{ }^{\circ} \mathrm{C} ;{ }^{1} \mathrm{H}$ NMR (400 MHz, DMSO- $\left.d_{6}\right): \delta 8.20-8.17$ (m, 4H, Ar- $H$ ), 7.95-7.85 (m, 4H, Ar$H+\mathrm{NH}), 7.36-7.29(\mathrm{~m}, 5 \mathrm{H}, \mathrm{Ar}-\mathrm{H}), 5.36\left(\mathrm{~s}, 2 \mathrm{H}, \mathrm{CH}_{2}\right.$-antrakinon), $5.07\left(\mathrm{~s}, 2 \mathrm{H}, \mathrm{PhCH}_{2} \mathrm{O}\right), 4.28-4.21(\mathrm{~m}$, $1 \mathrm{H}, \mathrm{CONHCH}), 1.36\left(\mathrm{~d}, 3 \mathrm{H}, \mathrm{CHCH}_{3}, J=8.0 \mathrm{~Hz}\right) .{ }^{13} \mathrm{C}$ NMR $\left(100 \mathrm{MHz}, \mathrm{DMSO}-d_{6}\right): \delta 182.8(C \mathrm{O}-$ anthraquinone), 182.6 (CO-anthraquinone), 173.2 (NHCHCO), $156.4\left(\mathrm{PhCH}_{2} \mathrm{OCO}\right), 143.4,137.4$, $135.1,135.0,133.6,133.5,133.4,132.9,128.8,128.3,128.3,127.6,127.2,127.2,125.8$ (Ar-C) 66.0 $\left(\mathrm{CH}_{2}\right.$-anthraquinone), $65.5\left(\mathrm{PhCH}_{2} \mathrm{OCO}\right), 49.9(\mathrm{CONHCH}), 17.3\left(\mathrm{CHCH}_{3}\right) . \mathrm{IR}\left(\mathrm{cm}^{-1}\right): v_{(\mathrm{C}=0) \text { ester: }} 1740$ $\mathrm{cm}^{-1}, v_{(\mathrm{C}=\mathrm{O}) \text { ketone }}: 1688 \mathrm{~cm}^{-1}, v_{(\mathrm{C}=\mathrm{O}) \text { carbamate }}: 1673 \mathrm{~cm}^{-1}, v_{(\mathrm{N}-\mathrm{H}) \text { amine }}: 3329 \mathrm{~cm}^{-1}$. Anal. calculated for $\mathrm{C}_{26} \mathrm{H}_{21} \mathrm{NO}_{6}$ ): C, 70.42; H, 4.77; N, 3.16. Found: $\mathrm{C}, 70.10 ; \mathrm{H}, 4.12 ; \mathrm{N}, 3.04$. HRMS m/z $\mathrm{C}_{26} \mathrm{H}_{21} \mathrm{NO}_{6}$ $[\mathrm{M}+\mathrm{H}]^{+}$calcd. 444.1, found 444.1; [M+NH$]^{+}$calcd. 461.2, found 461.1; [M+Na $]^{+}$calcd. 466.1, found 467.1; $[\mathrm{M}+\mathrm{K}]^{+}$calcd. 482.1, found 482.0; $\left[\mathrm{M}-\left(\mathrm{C}_{15} \mathrm{H}_{9} \mathrm{O}_{2}\right)\right]^{+}$calcd. 221.1, found 221.0.

(9,10-dioxo-9,10-dihydroanthracen-2-yl)methyl ((benzyloxy)carbonyl)-L-phenylalaninate (3): Cream (78\%);m.p.: 142-143 ${ }^{\circ} \mathrm{C}$; ${ }^{1} \mathrm{H}$ NMR (400 MHz, DMSO- $\left.d_{6}\right): \delta 8.22-8.16(\mathrm{~m}, 4 \mathrm{H}, \mathrm{Ar}-H), 7.97-7.93(\mathrm{~m}, 3 \mathrm{H}$, Ar- $H$ ), $7.78(\mathrm{~d}, 1 \mathrm{H}, \mathrm{NH}, J=8.0 \mathrm{~Hz}), 7.34-7.21(\mathrm{~m}, 10 \mathrm{H}, \mathrm{Ar}-H), 5.34$ (s, $2 \mathrm{H}, \mathrm{CH}_{2}$-anthraquinone), 5.06$4.98\left(\mathrm{~m}, 2 \mathrm{H}, \mathrm{PhCH}_{2} \mathrm{O}\right), 4.45-4.39(\mathrm{~m}, 1 \mathrm{H}, \mathrm{CONHCH}), 3.15$ and $3.11 \mathrm{dd}, 1 \mathrm{H}, \mathrm{CHCH}_{2} \mathrm{Ph}, J=4$ and $\left.8 \mathrm{~Hz}\right)$, 2.99 and $2.96\left(\mathrm{dd}, 1 \mathrm{H}, \mathrm{CHCH}_{2} \mathrm{Ph}, J=8\right.$ and $\left.12 \mathrm{~Hz}\right) .{ }^{13} \mathrm{C}$ NMR $\left(100 \mathrm{MHz}, \mathrm{DMSO}-d_{6}\right): \delta 182.7(\mathrm{CO}-$ anthraquinone), 182.6 (CO-anthraquinone), 172.2 (NHCHCO), $156.5\left(\mathrm{PhCH}_{2} \mathrm{OCO}\right), 143.2,137.7$, 137.3, 135.1, 135.0, 133.5, 133.5, 133.0, 129.6, 128.8, 128.8, 128.2, 128.1, 127.6, 127.3, 127.2, 127.0, $126.0(\mathrm{Ar}-\mathrm{C}) 66.0\left(\mathrm{CH}_{2}\right.$-anthraquinone), $65.7\left(\mathrm{PhCH}_{2} \mathrm{OCO}\right), 56.1(\mathrm{CONHCH}), 36.9\left(\mathrm{CHCH}_{2} \mathrm{Ph}\right) . \mathrm{IR}$ $\left(\mathrm{cm}^{-1}\right): v_{(\mathrm{C}=\mathrm{O}) \text { ester }}: 1725 \mathrm{~cm}^{-1}, v_{(\mathrm{C}=\mathrm{O}) \text { ketone }}: 1709 \mathrm{~cm}^{-1}, v_{(\mathrm{C}=\mathrm{O}) \text { carbamate: }} 1668 \mathrm{~cm}^{-1}, v_{(\mathrm{N}-\mathrm{H}) \text { amine: }}: 3360 \mathrm{~cm}^{-1}$. Anal. calculated for $\mathrm{C}_{32} \mathrm{H}_{25} \mathrm{NO}_{6}$ : C, 73.98; H, 4.85; N, 2.70. Found: C, 73.12; H, 4.74; N, 2.75. HRMS m/z $\mathrm{C}_{32} \mathrm{H}_{25} \mathrm{NO}_{6}[\mathrm{M}+\mathrm{H}]^{+}$calcd. 520.2, found 520.1; $\left[\mathrm{M}+\mathrm{NH}_{4}\right]^{+}$calcd. 537.2, found 537.2; [M+Na $]^{+}$calcd. 542.2, found 542.1; $[\mathrm{M}+\mathrm{K}]^{+}$calcd. 558.1, found 558.1; [M- $\left.\left(\mathrm{C}_{15} \mathrm{H}_{9} \mathrm{O}_{2}\right)\right]^{+}$calcd. 221.1, found 221.0.

(9,10-dioxo-9,10-dihydroanthracen-2-yl)methyl ((benzyloxy)carbonyl)-L-valinate (4): Cream (90\%); m.p.: $134-135{ }^{\circ} \mathrm{C} ;{ }^{1} \mathrm{H}$ NMR (400 MHz, DMSO- $\left.d_{6}\right): \delta 8.20-8.17(\mathrm{~m}, 4 \mathrm{H}, \mathrm{Ar}-H), 7.94-7.82(\mathrm{~m}, 4 \mathrm{H}, \mathrm{Ar}-$ $H+\mathrm{NH}), 7.38-7.25(\mathrm{~m}, 5 \mathrm{H}, \mathrm{Ar}-\mathrm{H}), 5.40-5.32\left(\mathrm{~m}, 2 \mathrm{H}, \mathrm{CH}_{2}\right.$ - anthraquinone), 5.11-5.04 (m, $\left.2 \mathrm{H}, \mathrm{PhCH}_{2} \mathrm{O}\right)$, 4.08-4.04 (m, 1H, OCONHCH), 2.17-2.08 (m, $\left.1 \mathrm{H}, \mathrm{CH}\left(\mathrm{CH}_{3}\right)_{2}\right), 0.92\left(\mathrm{~d}, 6 \mathrm{H}, \mathrm{CH}\left(\mathrm{CH}_{3}\right)_{2}, J=8.0 \mathrm{~Hz}\right) \cdot{ }^{13} \mathrm{C}$ NMR (100 MHz, DMSO- $d_{6}$ ): $\delta 182.7$ (CO- anthraquinone), 182.6 (CO- anthraquinone), 172.2 ( $\mathrm{NHCHCO}), 157.0\left(\mathrm{PhCH}_{2} \mathrm{OCO}\right), 143.3,137.4,135.1,135.0,133.7,133.5,133.4,133.0,128.8,128.3$, 128.3, 127.6, 127.2, 127.2, 126.0 (Ar- $C), 66.1\left(\mathrm{CH}_{2^{-}}\right.$anthraquinone), $65.5\left(\mathrm{PhCH}_{2} \mathrm{OCO}\right), 60.4$ $(\mathrm{CONHCH}), 30.1\left(\mathrm{CH}\left(\mathrm{CH}_{3}\right)_{2}\right), 19.5$ and $18.7\left(\mathrm{CH}\left(\mathrm{CH}_{3}\right)_{2}\right)$. IR $\left(\mathrm{cm}^{-1}\right): v_{(\mathrm{C}=0) \text { ester: }} 1725 \mathrm{~cm}^{-1}, v_{(\mathrm{C}=0) \text { ketone: }}$ : $1711 \mathrm{~cm}^{-1}, v_{(\mathrm{C}=\mathrm{O}) \text { carbamate: }} 1668 \mathrm{~cm}^{-1}, v_{(\mathrm{N}-\mathrm{H}) \text { amine: }}: 3370 \mathrm{~cm}^{-1}$. Anal. calculated for $\mathrm{C}_{28} \mathrm{H}_{25} \mathrm{NO}_{6}: \mathrm{C}, 71.33 ; \mathrm{H}$, 5.34; N, 2.97. Found: C, 71.12; H, 5.76; N, 3.08. HRMS $m / z \mathrm{C}_{28} \mathrm{H}_{25} \mathrm{NO}_{6}[\mathrm{M}+\mathrm{H}]^{+}$calcd. 472.2 , found 472.1; $\left[\mathrm{M}+\mathrm{NH}_{4}\right]^{+}$calcd. 489.2, found 489.1; $[\mathrm{M}+\mathrm{Na}]^{+}$calcd. 494.2, found 494.1; [M+K] ${ }^{+}$calcd. 510.1, found 511.2; [M- $\left.\left(\mathrm{C}_{15} \mathrm{H}_{9} \mathrm{O}_{2}\right)\right]^{+}$calcd. 221.1, found 221.0.

(9,10-dioxo-9,10-dihydroanthracen-2-yl)methyl ((benzyloxy)carbonyl)-L-leucinate (5): Cream (73\%); m.p.: 103-104 ${ }^{\circ} \mathrm{C} ;{ }^{1} \mathrm{H}$ NMR (400 MHz, DMSO- $\left.d_{6}\right)$ : $\delta$ 8.22-8.18 (m, 4H, Ar- $H$ ), 7.95-7.86 (m, 4H, Ar$H+\mathrm{NH})$, 7.36-7.21 (m, 5H, Ar-H), 5.40-5.32 (m, 2H, $\mathrm{CH}_{2}$ - anthraquinone), 5.11-5.03 (m, 2H, $\left.\mathrm{PhCH}_{2} \mathrm{O}\right)$, 4.22-4.16 (m, 1H, OCONHCH), 1.72-1.52 (m, 3H, $\left.\mathrm{CHCH}_{2} \mathrm{CH}\left(\mathrm{CH}_{3}\right)_{2}\right), 0.92-0.87(\mathrm{~m}, 6 \mathrm{H}$, $\left.\mathrm{CH}\left(\mathrm{CH}_{3}\right)_{2}\right) \cdot{ }^{13} \mathrm{C}$ NMR $\left(100 \mathrm{MHz}, \mathrm{DMSO}-d_{6}\right): \delta 182.8$ ( $\mathrm{CO}$ - anthraquinone), $182.6(\mathrm{CO}$ - anthraquinone), 173.1 ( $\mathrm{NHCHCO}), 156.7$ ( $\left.\mathrm{PhCH}_{2} \mathrm{OCO}\right), 143.4,137.4,135.1,135.0,133.6,133.5,133.0,128.8,128.3$, 128.2, 127.6, 127.3, 127.22, 125.8 (Ar-C), $66.1\left(\mathrm{CH}_{2}-\right.$ anthraquinone), $65.5\left(\mathrm{PhCH}_{2} \mathrm{OCO}\right), 52.9$ $(\mathrm{CONHCH}), 39.9\left(\mathrm{CHCH}_{2} \mathrm{CH}\left(\mathrm{CH}_{3}\right)_{2}\right), 24.8\left(\mathrm{CHCH}_{2} \mathrm{CH}\left(\mathrm{CH}_{3}\right)_{2}\right), 23.2$ and $21.7\left(\mathrm{CHCH}_{2} \mathrm{CH}\left(\mathrm{CH}_{3}\right)_{2}\right)$. IR $\left(\mathrm{cm}^{-1}\right): v_{(\mathrm{C}=O) \text { ester: }} 1722 \mathrm{~cm}^{-1}, v_{(\mathrm{C}=\mathrm{O}) \text { ketone: }} 1711 \mathrm{~cm}^{-1}, v_{(\mathrm{C}=\mathrm{O}) \text { carbamate: }} 1671 \mathrm{~cm}^{-1}, v_{(\mathrm{N}-\mathrm{H}) \text { amine: }}: 3370 \mathrm{~cm}^{-1}$. Anal. calculated for $\mathrm{C}_{29} \mathrm{H}_{27} \mathrm{NO}_{6}$ : C, 71.74; $\mathrm{H}, 5.61 ; \mathrm{N}, 2.88$. Found: $\mathrm{C}, 71.23 ; \mathrm{H}, 5.93 ; \mathrm{N}, 2.93$. HRMS $\mathrm{m} / \mathrm{z}$ $\mathrm{C}_{29} \mathrm{H}_{27} \mathrm{NO}_{6}[\mathrm{M}+\mathrm{H}]^{+}$calcd. 486.2, found 486.1; $\left[\mathrm{M}+\mathrm{NH}_{4}\right]^{+}$calcd. 503.2, found 504.2; [M+Na] ${ }^{+}$calcd. 508.2, found 508.1; $[\mathrm{M}+\mathrm{K}]^{+}$calcd. 524.2, found 525.1; [M- $\left.\left(\mathrm{C}_{15} \mathrm{H}_{9} \mathrm{O}_{2}\right)\right]^{+}$calcd. 221.1, found 221.0. 
(9,10-dioxo-9,10-dihydroanthracen-2-yl)methyl ((benzyloxy)carbonyl)-L-methioninate (6): Cream (91\%); m.p.: 153-154 ${ }^{\circ} \mathrm{C} ;{ }^{1} \mathrm{H}$ NMR (400 MHz, DMSO- $\left.d_{6}\right): \delta 8.21-8.17(\mathrm{~m}, 4 \mathrm{H}, \mathrm{Ar}-H), 7.95-7.91(\mathrm{~m}$, $3 \mathrm{H}, \operatorname{Ar}-H), 7.87(\mathrm{~d}, 1 \mathrm{H}, \mathrm{NH}, J=8.0 \mathrm{~Hz}), 7.36-7.29(\mathrm{~m}, 5 \mathrm{H}, \operatorname{Ar}-H), 5.40-5.33\left(\mathrm{~m}, 2 \mathrm{H}, \mathrm{CH}_{2}-\right.$ anthraquinone), 5.11-5.04 (m, $\left.2 \mathrm{H}, \mathrm{PhCH}_{2} \mathrm{O}\right), 4.38-4.31(\mathrm{~m}, 1 \mathrm{H}, \mathrm{OCONHCH}), 2.61-2.52(\mathrm{~m}, 2 \mathrm{H}$, $\mathrm{CHCH}_{2} \mathrm{CH}_{2} \mathrm{SCH}_{3}$ ), 2.04 (s, 3H, $\left.\mathrm{CHCH}_{2} \mathrm{CH}_{2} \mathrm{SCH}_{3}\right), 2.03-1.95$ (m, 2H, $\mathrm{CHCH}_{2} \mathrm{CH}_{2} \mathrm{SCH}_{3}$ ). ${ }^{13} \mathrm{C} \mathrm{NMR}^{2}(100$ $\mathrm{MHz}, \mathrm{DMSO}-d_{6}$ ): $\delta 182.7$ (CO- anthraquinone), 182.6 (CO- anthraquinone), 172.5 (NHCHCO), 156.7 $\left(\mathrm{PhCH}_{2} \mathrm{OCO}\right), 143.3,137.3,135.1,135.0,133.6,133.4,133.0,128.8,128.3,128.3,127.6,127.2,127.2$, 125.9 (Ar- $C), \quad 66.1 \quad\left(\mathrm{CH}_{2^{-}}\right.$anthraquinone), $65.7 \quad\left(\mathrm{PhCH}_{2} \mathrm{OCO}\right), \quad 53.3 \quad(\mathrm{CONHCH}), \quad 30.6$ $\left(\mathrm{CHCH}_{2} \mathrm{CH}_{2} \mathrm{SCH}_{3}\right), 30.0\left(\mathrm{CHCH}_{2} \mathrm{CH}_{2} \mathrm{SCH}_{3}\right), 14.9\left(\mathrm{CHCH}_{2} \mathrm{CH}_{2} \mathrm{SCH}_{3}\right)$. IR $\left(\mathrm{cm}^{-1}\right): v_{(\mathrm{C}=0) \text { ester: }} 1742 \mathrm{~cm}^{-1}$, $v_{(\mathrm{C}=0) \text { ketone: }} 1687 \mathrm{~cm}^{-1}, v_{(\mathrm{C}=\mathrm{O}) \text { carbamate: }}: 1673 \mathrm{~cm}^{-1}, v_{(\mathrm{N}-\mathrm{H}) \text { amine }}: 3327 \mathrm{~cm}^{-1}$. Anal. calculated for $\mathrm{C}_{28} \mathrm{H}_{25} \mathrm{NO}_{6} \mathrm{~S}$ : C, 66.78; H, 5.00; N, 2.78; S, 6.37. Found: C, 65.68; H, 4.59; N, 2.81; S, 6.14. HRMS m/z $\mathrm{C}_{28} \mathrm{H}_{25} \mathrm{NO}_{6} \mathrm{~S}$ $[\mathrm{M}+\mathrm{H}]^{+}$calcd. 504.1, found 504.1; $[\mathrm{M}+\mathrm{Na}]^{+}$calcd. 526.1, found 526.1; $[\mathrm{M}+\mathrm{K}]^{+}$calcd. 542.1, found 542.0; $\left[\mathrm{M}-\left(\mathrm{C}_{15} \mathrm{H}_{9} \mathrm{O}_{2}\right)\right]^{+}$calcd. 221.1, found 220.9.

(9,10-dioxo-9,10-dihydroanthracen-2-yl)methyl ((benzyloxy)carbonyl)-L-tryptophanate (7): Yellow (70\%); m.p.: 168-169 ${ }^{\circ} \mathrm{C} ;{ }^{1} \mathrm{H}$ NMR (400 MHz, DMSO- $\left.d_{6}\right): \delta 10.89$ (s, $1 \mathrm{H}$, indole-NH), 8.22-8.11 (m, $4 \mathrm{H}, \mathrm{Ar}-H), 7.97-7.93(\mathrm{~m}, 3 \mathrm{H}, \mathrm{Ar}-H+\mathrm{NH}), 7.63-7.60(\mathrm{~m}, 1 \mathrm{H}, \mathrm{Ar}-H), 7.54(\mathrm{~d}, 1 \mathrm{H}, \mathrm{Ar}-H, J=8.0 \mathrm{~Hz})$, 7.36-7.19 (m, 7H, Ar- $H$ ), 7.09-6.97 (m, 2H, Ar- $H$ ), 5.30 (s, 2H, CH $H_{2}$ anthraquinone), 5.07-4.98 (m, $2 \mathrm{H}$, $\mathrm{PhCH}_{2} \mathrm{O}$ ), 4.47-4.42 (m, 1H, OCONHCH), 3.27-3.22 (m, 1H, (3-indolyl) $\left.\mathrm{CH}_{2} \mathrm{CH}\right), 3.15-3.09(\mathrm{~m}, 1 \mathrm{H}$, (3-indolyl) $\left.\mathrm{CH}_{2} \mathrm{CH}\right) .{ }^{13} \mathrm{C}$ NMR $\left(100 \mathrm{MHz}, \mathrm{DMSO}-d_{6}\right): \delta 182.8(\mathrm{CO}-$ anthraquinone), $182.6(\mathrm{CO}-$ anthraquinone), 172.6 (NHCHCO), $156.5\left(\mathrm{PhCH}_{2} \mathrm{OCO}\right), 143.2,137.3,136.6,135.1,135.0,133.5$, 133.4, 132.9, 128.8, 128.3, 128.2, 127.5, 127.5, 127.3, 127.2, 125.9, 124.4, 121.5, 119.0, 118.5, 112.0, 109.9 (Ar- $\mathrm{C}), 66.0 \quad\left(\mathrm{CH}_{2}-\right.$ anthraquinone), $65.5 \quad\left(\mathrm{PhCH}_{2} \mathrm{OCO}\right), 55.7 \quad(\mathrm{CONHCH}), 27.4$ ((3indolyl) $\left.\mathrm{CH}_{2} \mathrm{CH}\right)$. IR $\left(\mathrm{cm}^{-1}\right): v_{(\mathrm{C}=0) \text { ester: }}: 1740 \mathrm{~cm}^{-1}, v_{(\mathrm{C}=0) \text { ketone }}: 1699 \mathrm{~cm}^{-1}, v_{(\mathrm{C}=0) \text { carbamate }}: 1669 \mathrm{~cm}^{-1}, v_{(\mathrm{N}-}$ H)amine: $3373,3337 \mathrm{~cm}^{-1}$. Anal. calculated for $\mathrm{C}_{34} \mathrm{H}_{26} \mathrm{~N}_{2} \mathrm{O}_{6}: \mathrm{C}, 73.11 ; \mathrm{H}, 4.69 ; \mathrm{N}, 5.02$. Found: $\mathrm{C}, 73.43$; $\mathrm{H}, 4.41 ; \mathrm{N}, 5.03$. HRMS m/z $\mathrm{C}_{34} \mathrm{H}_{26} \mathrm{~N}_{2} \mathrm{O}_{6}[\mathrm{M}+\mathrm{H}]^{+}$calcd. 559.2, found 559.1; [M+NH$]^{+}$calcd. 576.2, found 576.1; $[\mathrm{M}+\mathrm{Na}]^{+}$calcd. 581.2, found 581.1; $[\mathrm{M}+\mathrm{K}]^{+}$calcd. 579.1, found 579.1; [M-H] ${ }^{-}$calcd. 557.2, found 557.2.

(9,10-dioxo-9,10-dihydroanthracen-2-yl)methyl (tert-butoxycarbonyl)-L-alaninate (8): Cream (71\%); m.p.: $164-165{ }^{\circ} \mathrm{C}$; ${ }^{1} \mathrm{H}$ NMR (400 MHz, DMSO- $\left.d_{6}\right): \delta 8.17-8.13(\mathrm{~m}, 4 \mathrm{H}, \mathrm{Ar}-H)$, 7.94-7.92 (m, 3H, Ar- H+ $\mathrm{NH}), 7.43(\mathrm{~d}, 1 \mathrm{H}, \mathrm{Ar}-\mathrm{H}, J=8.0 \mathrm{~Hz}), 5.38-5.28\left(\mathrm{~m}, 2 \mathrm{H}, \mathrm{CH}_{2^{-}}\right.$anthraquinone $), 4.18-4.11(\mathrm{~m}, 1 \mathrm{H}$, OCONHCH), $1.38\left(\mathrm{~s}, 9 \mathrm{H}, \mathrm{OC}\left(\mathrm{CH}_{3}\right)_{3}\right), 1.32\left(\mathrm{~d}, 3 \mathrm{H}, \mathrm{CHCH}_{3}, J=8.0 \mathrm{~Hz}\right) \cdot{ }^{13} \mathrm{C}$ NMR $\left(100 \mathrm{MHz}, \mathrm{DMSO}-d_{6}\right)$ : $\delta 182.7$ (CO- anthraquinone), 182.5 (CO- anthraquinone), $173.4(\mathrm{NHCHCO}), 155.8\left(\left(\mathrm{CH}_{3}\right)_{3} \mathrm{COCO}\right)$, 143.5, 135.1, 135.0, 133.5, 133.4, 132.9, 127.5, 127.2, 127.2, $125.8(\mathrm{Ar}-\mathrm{C}), 78.7\left(\left(\mathrm{CH}_{3}\right)_{3} \mathrm{COCO}\right), 65.4$ $\left(\mathrm{CH}_{2}\right.$ - anthraquinone), $49.6(\mathrm{CONHCH}), 28.6\left(\mathrm{OC}\left(\mathrm{CH}_{3}\right)_{3}\right), 17.3\left(\mathrm{CHCH}_{3}\right) . \mathrm{IR}\left(\mathrm{cm}^{-1}\right): v_{(\mathrm{C}=0) \text { ester: }} 1747 \mathrm{~cm}^{-}$ ${ }^{1}, v_{(\mathrm{C}=\mathrm{O}) \text { ketone: }} 1687 \mathrm{~cm}^{-1}, v_{(\mathrm{C}=\mathrm{O}) \text { carbamate }}: 1673 \mathrm{~cm}^{-1}, v_{(\mathrm{N}-\mathrm{H}) \text { amine: }} 3364 \mathrm{~cm}^{-1}$. Anal. calculated for $\mathrm{C}_{23} \mathrm{H}_{23} \mathrm{NO}_{6}$ : $\mathrm{C}$, 67.47; H, 5.66; N, 3.42. Found: C, 66.90; $\mathrm{H}, 5.14 ; \mathrm{N}, 3.26$. HRMS $m / z \mathrm{C}_{23} \mathrm{H}_{23} \mathrm{NO}_{6}[\mathrm{M}+\mathrm{Na}]^{+}$calcd. 432.2, found 432.1; $[\mathrm{M}+\mathrm{K}]^{+}$calcd. 448.1, found 448.2; $\left[\mathrm{M}-\left(\mathrm{C}_{15} \mathrm{H}_{9} \mathrm{O}_{2}\right)\right]^{+}$calcd. 221.1, found 221.0.

(9,10-dioxo-9,10-dihydroanthracen-2-yl)methyl (tert-butoxycarbonyl)-L-phenylalaninate (9): Yellow (90\%); m.p.: $130-131{ }^{\circ} \mathrm{C} ;{ }^{1} \mathrm{H}$ NMR (400 MHz, DMSO- $\left.d_{6}\right)$ : $\delta$ 8.21-8.15 (m, 4H, Ar-H), 7.95-7.91 (m, $2 \mathrm{H}, \mathrm{Ar}-H), 7.78(\mathrm{~d}, 1 \mathrm{H}, \mathrm{NH}, J=8.0 \mathrm{~Hz}), 7.47(\mathrm{~d}, 1 \mathrm{H}, \mathrm{Ar}-H, J=8.0 \mathrm{~Hz}), 7.31-7.19(\mathrm{~m}, 5 \mathrm{H}, \mathrm{Ar}-H), 5.32$ (s, $2 \mathrm{H}, \mathrm{CH}_{2}$ - anthraquinone), 4.33-4.27 (m, 1H, OCONHCH), 3.09-3.04 (m, 1H, $\left.\mathrm{CHCH}_{2} \mathrm{Ph}\right), 2.98-2.92$ $\left(\mathrm{m}, 1 \mathrm{H}, \mathrm{CHCH}_{2} \mathrm{Ph}\right), 1.33\left(\mathrm{~s}, 9 \mathrm{H}, \mathrm{OC}\left(\mathrm{CH}_{3}\right)_{3}\right) \cdot{ }^{13} \mathrm{C} \mathrm{NMR}\left(100 \mathrm{MHz}, \mathrm{DMSO}-d_{6}\right): \delta 182.7(\mathrm{CO}-$ anthraquinone), 182.6 (CO- anthraquinone), 172.5 ( $\mathrm{NHCHCO}), 155.9\left(\left(\mathrm{CH}_{3}\right)_{3} \mathrm{COCO}\right), 143.2,137.9$, 135.0, 133.6, 133.5, 133.5, 133.4, 132.9, 129.6, 128.7, 127.5, 127.3, 127.2, 127.0, 126.0 (Ar-C), 78.9 $\left(\left(\mathrm{CH}_{3}\right)_{3} \mathrm{COCO}\right), 65.5\left(\mathrm{CH}_{2}\right.$ - anthraquinone), $55.9(\mathrm{CONHCH}), 36.8\left(\mathrm{CHCH}_{2} \mathrm{Ph}\right), 28.6\left(\mathrm{OC}\left(\mathrm{CH}_{3}\right)_{3}\right)$. IR $\left(\mathrm{cm}^{-1}\right): v_{(\mathrm{C}=\mathrm{O}) \text { ester: }}: 1728 \mathrm{~cm}^{-1}, v_{(\mathrm{C}=\mathrm{O}) \text { ketone: }} 1688 \mathrm{~cm}^{-1}, v_{(\mathrm{C}=\mathrm{O}) \text { carbamate: }} 1676 \mathrm{~cm}^{-1}, v_{(\mathrm{N}-\mathrm{H}) \text { amine: }} 3341 \mathrm{~cm}^{-1}$. Anal. calculated for $\mathrm{C}_{29} \mathrm{H}_{27} \mathrm{NO}_{6}$ : C, 71.74; $\mathrm{H}, 5.61 ; \mathrm{N}, 2.88$. Found: $\mathrm{C}, 71.42 ; \mathrm{H}, 5.94 ; \mathrm{N}, 3.09$. HRMS $\mathrm{m} / \mathrm{z}$ $\mathrm{C}_{29} \mathrm{H}_{27} \mathrm{NO}_{6}[\mathrm{M}+\mathrm{H}]^{+}$calcd. 486.2, found 586.1; $\left[\mathrm{M}+\mathrm{NH}_{4}\right]^{+}$calcd. 503.2, found 503.2; $[\mathrm{M}+\mathrm{Na}]^{+}$calcd. 
Küçükbay et al., Org. Commun. (2021) 14:3 255-269

508.2, found 508.2; $[\mathrm{M}+\mathrm{HCOOH}]^{+}$calcd. 531.2, found 531.2; $\left[\mathrm{M}-\left(\mathrm{C}_{15} \mathrm{H}_{9} \mathrm{O}_{2}\right)\right]^{+}$calcd. 221.1, found 221.0.

(9,10-dioxo-9,10-dihydroanthracen-2-yl)methyl (tert-butoxycarbonyl)-L-valinate (10): White (62\%); m.p.: $136-137{ }^{\circ} \mathrm{C} ;{ }^{1} \mathrm{H}$ NMR (400 MHz, DMSO- $\left.d_{6}\right): \delta 8.22-8.18(\mathrm{~m}, 4 \mathrm{H}, \mathrm{Ar}-H), 7.96-7.89(\mathrm{~m}, 3 \mathrm{H}, \mathrm{Ar}-H$ $+\mathrm{NH}), 7.33(\mathrm{~d}, 1 \mathrm{H}, \mathrm{Ar}-\mathrm{H}, J=8.0 \mathrm{~Hz}), 5.40-5.31\left(\mathrm{~m}, 2 \mathrm{H}, \mathrm{CH}_{2}-\right.$ anthraquinone $), 3.97-3.93(\mathrm{~m}, 1 \mathrm{H}$, OCONHCH $), 2.12-2.02\left(\mathrm{~m}, 1 \mathrm{H}, \mathrm{CH}\left(\mathrm{CH}_{3}\right)_{2}\right), 1.39\left(\mathrm{~s}, 9 \mathrm{H}, \mathrm{OC}\left(\mathrm{CH}_{3}\right)_{3}\right), 0.90\left(\mathrm{~d}, 6 \mathrm{H}, \mathrm{CH}\left(\mathrm{CH}_{3}\right)_{2}, J=8.0\right.$ $\mathrm{Hz}) .{ }^{13} \mathrm{C}$ NMR (100 MHz, DMSO- $\left.d_{6}\right): \delta 182.7$ (CO- anthraquinone), 182.6 (CO- anthraquinone), 172.4 ( $\mathrm{NHCHCO}), 156.3\left(\left(\mathrm{CH}_{3}\right)_{3} \mathrm{COCO}\right), 143.4,135.1,135.1,133.7,133.6,133.5,133.0,127.5,127.3,127.2$, 126.1 (Ar- $\mathrm{C}), 78.8\left(\left(\mathrm{CH}_{3}\right)_{3} \mathrm{COCO}\right), 65.3\left(\mathrm{CH}_{2^{-}}\right.$anthraquinone), $60.1(\mathrm{CONHCH}), 30.0\left(\mathrm{CH}\left(\mathrm{CH}_{3}\right)_{2}\right)$, $28.6\left(\mathrm{OC}\left(\mathrm{CH}_{3}\right)_{3}\right), 19.5$ and $18.9\left(\mathrm{CH}\left(\mathrm{CH}_{3}\right)_{2}\right)$. IR $\left(\mathrm{cm}^{-1}\right): v_{(\mathrm{C}=0) \text { ester: }} 1736 \mathrm{~cm}^{-1}, v_{(\mathrm{C}=0) \text { carbamate: }} 1674 \mathrm{~cm}^{-1}$, $v_{(\mathrm{C}=0) \text { ketone: }} 1687 \mathrm{~cm}^{-1}, v_{(\mathrm{N}-\mathrm{H}) \text { amine: }} 3348 \mathrm{~cm}^{-1}$. Anal. calculated for $\mathrm{C}_{25} \mathrm{H}_{27} \mathrm{NO}_{6}: \mathrm{C}, 68.64 ; \mathrm{H}, 6.22 ; \mathrm{N}, 3.20$. Found: C, 68.38; H, 6.83; N, 3.21. HRMS m/z $\mathrm{C}_{25} \mathrm{H}_{27} \mathrm{NO}_{6}[\mathrm{M}+\mathrm{Na}]^{+}$calcd. 460.1, found 460.2; [M+K] ${ }^{+}$ calcd. 476.1, found 476.2; [M- $\left.\left(\mathrm{C}_{15} \mathrm{H}_{9} \mathrm{O}_{2}\right)\right]^{+}$calcd. 221.1, found 221.0.

(9,10-dioxo-9,10-dihydroanthracen-2-yl)methyl (tert-butoxycarbonyl)-L-alloisoleucinate (11): White (72\%); m.p.: $113-114{ }^{\circ} \mathrm{C} ;{ }^{1} \mathrm{H}$ NMR (400 MHz, DMSO- $\left.d_{6}\right): \delta 8.21-8.17(\mathrm{~m}, 4 \mathrm{H}, \mathrm{Ar}-H), 7.95-7.88(\mathrm{~m}$, $3 \mathrm{H}, \mathrm{Ar}-H+\mathrm{NH}), 7.33(\mathrm{~d}, 1 \mathrm{H}, \mathrm{Ar}-H, J=8.0 \mathrm{~Hz}), 5.40-5.30\left(\mathrm{~m}, 2 \mathrm{H}, \mathrm{CH}_{2}\right.$-anthraquinone), 4.02-3.98 (m, 1H, OCONHCH $), 1.86-1.79\left(\mathrm{~m}, 1 \mathrm{H}, \mathrm{CHCH}\left(\mathrm{CH}_{3}\right) \mathrm{CH}_{2} \mathrm{CH}_{3}\right), 1.39\left(\mathrm{~s}, 9 \mathrm{H}, \mathrm{OC}\left(\mathrm{CH}_{3}\right)_{3}\right), 1.28-1.18(\mathrm{~m}, 2 \mathrm{H}$, $\left.\mathrm{CHCH}\left(\mathrm{CH}_{3}\right) \mathrm{CH}_{2} \mathrm{CH}_{3}\right), 0.87-0.81\left(\mathrm{~m}, 6 \mathrm{H}, \mathrm{CHCH}\left(\mathrm{CH}_{3}\right) \mathrm{CH}_{2} \mathrm{CH}_{3}\right) .{ }^{13} \mathrm{C}$ NMR $\left(100 \mathrm{MHz}, \mathrm{DMSO}-d_{6}\right): \delta$ 182.7 (CO-anthraquinone), 182.6 (CO-anthraquinone), 172.4 ( $\mathrm{NHCHCO}), 156.2\left(\left(\mathrm{CH}_{3}\right)_{3} \mathrm{COCO}\right)$, 143.4, 135.1, 135.0, 133.7, 133.5, 133.5, 133.0, 127.5, 127.2, 127.2, $126.1(\mathrm{Ar}-\mathrm{C}), 78.8\left(\left(\mathrm{CH}_{3}\right)_{3} \mathrm{COCO}\right)$, $65.3\left(\mathrm{CH}_{2}\right.$-anthraquinone), $58.9(\mathrm{CONHCH}), 36.4\left(\mathrm{CHCH}\left(\mathrm{CH}_{3}\right) \mathrm{CH}_{2} \mathrm{CH}_{3}\right), 28.6\left(\mathrm{OC}\left(\mathrm{CH}_{3}\right)_{3}\right), 25.4$ $\left(\mathrm{CHCH}\left(\mathrm{CH}_{3}\right) \mathrm{CH}_{2} \mathrm{CH}_{3}\right), 16.0\left(\mathrm{CHCH}\left(\mathrm{CH}_{3}\right) \mathrm{CH}_{2} \mathrm{CH}_{3}\right), 11.6\left(\mathrm{CHCH}\left(\mathrm{CH}_{3}\right) \mathrm{CH}_{2} \mathrm{CH}_{3}\right)$. IR $\left(\mathrm{cm}^{-1}\right): v_{(\mathrm{C}=0) \text { ester: }}$ : $1736 \mathrm{~cm}^{-1}, v_{(\mathrm{C}=\mathrm{O}) \text { ketone: }} 1682 \mathrm{~cm}^{-1}, v_{(\mathrm{C}=\mathrm{O}) \text { carbamate }}: 1674 \mathrm{~cm}^{-1}, v_{(\mathrm{N}-\mathrm{H}) \text { amine: }} 3351 \mathrm{~cm}^{-1}$. Anal. calculated for $\mathrm{C}_{26} \mathrm{H}_{29} \mathrm{NO}_{6}$ : C, 69.16; H, 6.47; N, 3.10. Found: C, 69.96; H, 6.50; N, 2.85. HRMS $m / z \mathrm{C}_{26} \mathrm{H}_{29} \mathrm{NO}_{6}$ $[\mathrm{M}+\mathrm{Na}]^{+}$calcd. 474.2, found 474.1; $[\mathrm{M}+\mathrm{K}]^{+}$calcd. 490.1, found 490.2; [M- $\left.\left(\mathrm{C}_{15} \mathrm{H}_{9} \mathrm{O}_{2}\right)\right]^{+}$calcd. 221.1, found 221.0 .

(9,10-dioxo-9,10-dihydroanthracen-2-yl)methyl (tert-butoxycarbonyl)-L-methioninate (12): Cream (89\%); m.p.: $117-118{ }^{\circ} \mathrm{C} ;{ }^{1} \mathrm{H}$ NMR (400 MHz, DMSO- $\left.d_{6}\right): \delta 8.23-8.20(\mathrm{~m}, 4 \mathrm{H}, \mathrm{Ar}-H), 7.96-7.89(\mathrm{~m}$, $3 \mathrm{H}, \mathrm{Ar}-\mathrm{H}+\mathrm{NH}), 7.45(\mathrm{~d}, 1 \mathrm{H}, \mathrm{Ar}-\mathrm{H}, \mathrm{J}=8.0 \mathrm{~Hz}), 5.41-5.32\left(\mathrm{~m}, 2 \mathrm{H}, \mathrm{CH}_{2}\right.$ - anthraquinone), 4.25-4.20 (m, $1 \mathrm{H}, \mathrm{OCONHCH}$ ), 2.57-2.51 (m, $\left.2 \mathrm{H}, \mathrm{CHCH}_{2} \mathrm{CH}_{2} \mathrm{SCH}_{3}\right), 2.04$ (s, 3H, $\left.\mathrm{CHCH}_{2} \mathrm{CH}_{2} \mathrm{SCH}_{3}\right), 1.99-1.92(\mathrm{~m}$, $\left.2 \mathrm{H}, \mathrm{CHCH}_{2} \mathrm{CH}_{2} \mathrm{SCH}_{3}\right), 1.39$ (s, 9H, OC( $\left.\left.\mathrm{CH}_{3}\right)_{3}\right) .{ }^{13} \mathrm{C} \mathrm{NMR}\left(100 \mathrm{MHz}, \mathrm{DMSO}-d_{6}\right): \delta 182.8(\mathrm{CO}-$ anthraquinone), 182.6 (CO- anthraquinone), 172.7 ( $\mathrm{NHCHCO}), 156.1\left(\left(\mathrm{CH}_{3}\right)_{3} \mathrm{COCO}\right), 143.4,135.1$, 133.6, 133.5, 133.0, 127.5, 127.3, 127.2, $126.0(\mathrm{Ar}-\mathrm{C}), 78.9\left(\left(\mathrm{CH}_{3}\right)_{3} \mathrm{COCO}\right), 65.6\left(\mathrm{CH}_{2}\right.$ - anthraquinone), $53.1(\mathrm{CONHCH}), \quad 30.6\left(\mathrm{CHCH}_{2} \mathrm{CH}_{2} \mathrm{SCH}_{3}\right), \quad 30.1 \quad\left(\mathrm{CHCH}_{2} \mathrm{CH}_{2} \mathrm{SCH}_{3}\right), 28.6\left(\mathrm{OC}\left(\mathrm{CH}_{3}\right)_{3}\right), \quad 15.0$ $\left(\mathrm{CHCH}_{2} \mathrm{CH}_{2} \mathrm{SCH}_{3}\right)$. IR $\left(\mathrm{cm}^{-1}\right): v_{(\mathrm{C}=0) \text { ester }}: 1733 \mathrm{~cm}^{-1}, v_{(\mathrm{C}=0) \text { ketone: }} 1688 \mathrm{~cm}^{-1}, v_{(\mathrm{C}=0) \text { carbamate: }} 1674 \mathrm{~cm}^{-1}, v_{(\mathrm{N}-}$ H)amine: $3348 \mathrm{~cm}^{-1}$. Anal. calculated for $\mathrm{C}_{25} \mathrm{H}_{27} \mathrm{NO}_{6} \mathrm{~S}: \mathrm{C}, 63.95 ; \mathrm{H}, 5.80 ; \mathrm{N}, 2.98 ; \mathrm{S}, 6.83$. Found: C, 63.98; $\mathrm{H}, 5.27 ; \mathrm{N}, 3.09 ; \mathrm{S}, 6.67$. HRMS $m / z \mathrm{C}_{25} \mathrm{H}_{27} \mathrm{NO}_{6} \mathrm{~S}[\mathrm{M}+\mathrm{Na}]^{+}$calcd. 492.2, found 492.1; $[\mathrm{M}+\mathrm{K}]^{+}$calcd. 508.1, found 508.1; [M- $\left.\left(\mathrm{C}_{15} \mathrm{H}_{9} \mathrm{O}_{2}\right)\right]^{+}$calcd. 221.1, found 221.0.

(9,10-dioxo-9,10-dihydroanthracen-2-yl)methyl (tert-butoxycarbonyl)-L-tryptophanate (13):Yellow (75\%); m.p.: 154-155 ${ }^{\circ} \mathrm{C} ;{ }^{1} \mathrm{H}$ NMR (400 MHz, DMSO- $\left.d_{6}\right): \delta 10.87$ (s, $1 \mathrm{H}$, indole-NH), 8.23-8.12 (m, $4 \mathrm{H}, \operatorname{Ar}-H), 7.97-7.92(\mathrm{~m}, 2 \mathrm{H}, \mathrm{Ar}-H+\mathrm{NH}), 7.64(\mathrm{~d}, 1 \mathrm{H}, \operatorname{Ar}-H, J=8.0 \mathrm{~Hz}), 7.52(\mathrm{~d}, 1 \mathrm{H}, \operatorname{Ar}-H, J=8.0$ $\mathrm{Hz}), 7.41$ (d, $1 \mathrm{H}, \mathrm{Ar}-H, J=8.0 \mathrm{~Hz}), 7.34$ (d, $1 \mathrm{H}, \mathrm{Ar}-H, J=8.0 \mathrm{~Hz}$ ), 7.18 (bs, $1 \mathrm{H}, \mathrm{Ar}-H), 7.08-6.98$ (m, $2 \mathrm{H}, \mathrm{Ar}-\mathrm{H}), 5.29$ (s, $2 \mathrm{H}, \mathrm{CH}_{2}$-anthraquinone), 4.37-4.31 (m, 1H, OCONHCH), 3.22-3.17 (m, $1 \mathrm{H}$, (3indolyl) $\left.\mathrm{CH}_{2} \mathrm{CH}\right), 3.12-3.06\left(\mathrm{~m}, 1 \mathrm{H},(3-\right.$ indolyl $\left.) \mathrm{CH}_{2} \mathrm{CH}\right), 1.35\left(\mathrm{~s}, 9 \mathrm{H}, \mathrm{OC}\left(\mathrm{CH}_{3}\right)_{3}\right) .{ }^{13} \mathrm{C} \mathrm{NMR}(100 \mathrm{MHz}$, DMSO- $\left.d_{6}\right): \delta 182.7$ (CO- anthraquinone), 182.6 (CO- anthraquinone), 172.8 (NHCHCO), 155.9 $\left(\left(\mathrm{CH}_{3}\right)_{3} \mathrm{COCO}\right), 143.3,136.6,135.1,133.5,133.5,133.4,132.9,127.5,127.4,127.3,127.2,126.0$, 
Monopeptide-anthraquinone conjugates

124.3, 121.4, 118.9, 118.5, 111.9, $110.0(\mathrm{Ar}-\mathrm{C}), 78.8\left(\left(\mathrm{CH}_{3}\right)_{3} \mathrm{COCO}\right), 65.4\left(\mathrm{CH}_{2}\right.$ - anthraquinone $), 55.4$ $(\mathrm{CONHCH}), 28.6\left(\mathrm{OC}\left(\mathrm{CH}_{3}\right)_{3}\right), 27.3\left((3\right.$-indolyl $\left.) \mathrm{CH}_{2} \mathrm{CH}\right)$. IR $\left(\mathrm{cm}^{-1}\right): v_{(\mathrm{C}=0) \text { ester: }} 1748 \mathrm{~cm}^{-1}, v_{(\mathrm{C}=0) \text { ketone: }}$ : $1689 \mathrm{~cm}^{-1}, v_{(\mathrm{C}=\mathrm{O}) \text { carbamate }}: 1676 \mathrm{~cm}^{-1}, v_{(\mathrm{N}-\mathrm{H}) \text { amine }}: 3397,3350 \mathrm{~cm}^{-1}$. Anal. calculated for $\mathrm{C}_{31} \mathrm{H}_{28} \mathrm{~N}_{2} \mathrm{O}_{6}: \mathrm{C}$, 70.98; H, 5.38; N, 5.34. Found: C, 70.35; H, 5.45; N, 5.78. HRMS $m / z \mathrm{C}_{31} \mathrm{H}_{28} \mathrm{~N}_{2} \mathrm{O}_{6}[\mathrm{M}+\mathrm{Na}]^{+}$calcd. 547.2, found 547.1; $[\mathrm{M}+\mathrm{K}]^{+}$calcd. 563.2, found 563.1; [M-H] ${ }^{-}$calcd. 523.2, found 523.1; $[\mathrm{M}+\mathrm{Cl}]^{-}$calcd. 559.2, found 559.1; [M- $\left.\left(\mathrm{C}_{15} \mathrm{H}_{9} \mathrm{O}_{2}\right)\right]^{+}$calcd. 221.1, found 221.1.

(9,10-dioxo-9,10-dihydroanthracen-2-yl)methyl (((9H-fluoren-9-yl)methoxy)carbonyl)glycinate (14): Yellow (88\%); m.p.: $180-181{ }^{\circ} \mathrm{C} ;{ }^{1} \mathrm{H}$ NMR (400 MHz, DMSO- $\left.d_{6}\right): \delta 8.18-8.11(\mathrm{~m}, 4 \mathrm{H}, \mathrm{Ar}-H)$, $7.92-$ $7.80(\mathrm{~m}, 6 \mathrm{H}, \mathrm{Ar}-\mathrm{H}+\mathrm{NH}), 7.67(\mathrm{~d}, 2 \mathrm{H}, \mathrm{Ar}-H, J=8.0 \mathrm{~Hz}), 7.39-7.27(\mathrm{~m}, 4 \mathrm{H}, \mathrm{Ar}-\mathrm{H}), 5.34\left(\mathrm{~s}, 2 \mathrm{H}, \mathrm{CH}_{2^{-}}\right.$ anthraquinone), 4.32 (d, $2 \mathrm{H}, \mathrm{CHCH}_{2} \mathrm{OCO}, J=8.0 \mathrm{~Hz}$ ), 4.18 (t, $\left.1 \mathrm{H}, \mathrm{CHCH}_{2} \mathrm{OCO}, J=6.0 \mathrm{~Hz}\right), 3.93$ (d, $\left.2 \mathrm{H}, \mathrm{OCONHCH}_{2}, J=8.0 \mathrm{~Hz}\right) .{ }^{13} \mathrm{C}$ NMR $\left(100 \mathrm{MHz}\right.$, DMSO- $\left.d_{6}\right): \delta 182.6(\mathrm{CO}$ - anthraquinone), 182.5 (CO- anthraquinone), $170.6\left(\mathrm{NHCH}_{2} \mathrm{CO}\right), 157.1\left(\mathrm{CHCH}_{2} \mathrm{OCO}\right), 144.2,143.1,141.1,135.0,135.0$, $133.8,133.5,133.4,132.9,128.0,127.5,127.2,127.2,126.1,125.6,120.5(\mathrm{Ar}-\mathrm{C}), 66.3\left(\mathrm{CH}_{2-}\right.$ anthraquinone), $65.6\left(\mathrm{CHCH}_{2} \mathrm{OCO}\right), 47.0\left(\mathrm{CHCH}_{2} \mathrm{OCO}\right), 42.8\left(\mathrm{OCONHCH}_{2}\right) . \mathrm{IR}\left(\mathrm{cm}^{-1}\right): v_{(\mathrm{C}=0) \text { ester }}: 1765$ $\mathrm{cm}^{-1}, v_{(\mathrm{C}=O) \text { ketone }}: 1704 \mathrm{~cm}^{-1}, v_{(\mathrm{C}=\mathrm{O}) \text { carbamate }}: 1673 \mathrm{~cm}^{-1}, v_{(\mathrm{N}-\mathrm{H}) \text { amine }}: 3343 \mathrm{~cm}^{-1}$. Anal. calculated for $\mathrm{C}_{32} \mathrm{H}_{23} \mathrm{NO}_{6}$ : C, 74.27; H, 4.48; N, 2.71. Found: C, 74.03; H, 4.05; N, 2.57. HRMS m/z $\mathrm{C}_{32} \mathrm{H}_{23} \mathrm{NO}_{6}$ $[\mathrm{M}+\mathrm{H}]^{+}$calcd. 518.2, found 518.1; $\left[\mathrm{M}+\mathrm{NH}_{4}\right]^{+}$calcd. 535.2, found 535.1; $[\mathrm{M}+\mathrm{Na}]^{+}$calcd. 540.1, found 540.1; $[\mathrm{M}+\mathrm{K}]^{+}$calcd. 556.2, found 556.1; $\left[\mathrm{M}-\left(\mathrm{C}_{15} \mathrm{H}_{9} \mathrm{O}_{2}\right)\right]^{+}$calcd. 221.1, found 221.0.

(9,10-dioxo-9,10-dihydroanthracen-2-yl)methyl(((9H-fluoren-9-yl)methoxy)carbonyl)-L-

phenylalaninate (15): Yellow (\%78); m.p.: 198-199 ${ }^{\circ} \mathrm{C} ;{ }^{1} \mathrm{H}$ NMR (400 MHz, DMSO- $d_{6}$ ): $\delta$ 8.19-8.03 (m, 5H, Ar- $H$ ), 7.93 (bs, 2H, Ar- $H+\mathrm{NH}), 7.77$ (d, 2H, Ar- $H, J=8.0 \mathrm{~Hz}), 7.59$ (t, 2H, Ar- $H, J=8.0 \mathrm{~Hz}$ ), 7.36-7.22 (m, 10H, Ar- $H$ ), 5.33 (s, $2 \mathrm{H}, \mathrm{CH}_{2}$ anthraquinone), 4.43-4.28 (m, 2H, $\left.\mathrm{CHCH}_{2} \mathrm{OCO}\right), 4.19-$ $4.08\left(\mathrm{~m}, 2 \mathrm{H}, \mathrm{CHCH}_{2} \mathrm{OCONHCH}\right), \quad 3.18-3.13\left(\mathrm{~m}, 1 \mathrm{H}, \mathrm{CHCH}_{2} \mathrm{Ph}\right), 3.03-2.97\left(\mathrm{~m}, 1 \mathrm{H}, \mathrm{CHCH}_{2} \mathrm{Ph}\right) .{ }^{13} \mathrm{C}$ NMR (100 MHz, DMSO- $\left.d_{6}\right): \delta 182.6$ (CO- anthraquinone), 182.5 (CO- anthraquinone), 172.1 (NHCHCO), $156.5\left(\mathrm{CHCH}_{2} \mathrm{OCO}\right), 144.2,144.1,143.0,141.1,137.9,135.0,133.7,133.5,133.4,132.9$, 129.6, 128.6, 128.0, 127.4, 127.2, 127.2, 127.0, 126.1, 125.6, 120.5 (Ar-C), $66.2\left(\mathrm{CH}_{2}\right.$ - anthraquinone), $65.7\left(\mathrm{CHCH}_{2} \mathrm{OCO}\right), 56.1(\mathrm{CONHCH}), 46.9\left(\mathrm{CHCH}_{2} \mathrm{OCO}\right), 36.7\left(\mathrm{CHCH}_{2} \mathrm{Ph}\right) . \mathrm{IR}\left(\mathrm{cm}^{-1}\right): v_{(\mathrm{C}=0) \text { ester }}: 1742$ $\mathrm{cm}^{-1}, v_{(\mathrm{C}=\mathrm{O}) \text { ketone }}: 1702 \mathrm{~cm}^{-1}, v_{(\mathrm{C}=\mathrm{O}) \text { carbamate }}: 1677 \mathrm{~cm}^{-1}, v_{(\mathrm{N}-\mathrm{H}) \text { amine }}: 3314 \mathrm{~cm}^{-1}$. Anal. calculated for $\mathrm{C}_{39} \mathrm{H}_{29} \mathrm{NO}_{6}: \mathrm{C}, 77.09 ; \mathrm{H}, 4.81 ; \mathrm{N}, 2.31$. Found: C, 77.61; H, 4.55; N, 2.00. HRMS m/z $\mathrm{C}_{39} \mathrm{H}_{29} \mathrm{NO}_{6}$ $[\mathrm{M}+\mathrm{H}]^{+}$calcd. 608.2 , found $608.2 ;\left[\mathrm{M}+\mathrm{NH}_{4}\right]^{+}$calcd. 625.2, found 625.1; [ [M+K $]^{+}$calcd. 646.2, found 646.1; [M- $\left.\left(\mathrm{C}_{15} \mathrm{H}_{9} \mathrm{O}_{2}\right)\right]^{+}$calcd. 221.1, found 221.0.

Synthesis of (S)-1-((9,10-dioxo-9,10-dihydroanthracen-2-yl)methoxy)-1-oxo-3-phenylpropan-2aminium 2,2,2-trifluoroacetate (16)

(9,10-Dioxo-9,10-dihydroanthracen-2-yl)methyl (tert-butoxycarbonyl)-L-phenylalaninate (9) $(0.15 \mathrm{mmol})$ was dissolved in TFA /DCM mixture $(1.5 / 1.5 \mathrm{~mL})$ and stirred for 2 hours at room temperature according to the literature method. ${ }^{38}$ The reaction mixture was concentrated at reduced pressure, and the excess of diethyl ether was added to afford the desired cream powder. This powder was filtered and air-dried. Cream solid (89\%); m.p. $167-168{ }^{\circ} \mathrm{C} ;{ }^{1} \mathrm{H}$ NMR (400 MHz, DMSO) $\delta 8.65$ (s, $\left.3 \mathrm{H}, \mathrm{N} H^{+}{ }_{3}\right), 8.23-8.15(\mathrm{~m}, 4 \mathrm{H}, \mathrm{Ar}-H)$, 7.97-7.94 (m, $\left.2 \mathrm{H}, \mathrm{Ar}-H\right), 7.71(\mathrm{~d}, 1 \mathrm{H}, \mathrm{Ar}-H, J=8 \mathrm{~Hz}), 7.33-7.24$ (m, 5H, Ar-H), 5.41-5.33 (m, 2H, OCH ${ }_{2}$-anthraquinone), $4.48\left(\mathrm{t}, 1 \mathrm{H}, \mathrm{CHCH}_{2} \mathrm{Ph}, J=8 \mathrm{~Hz}\right), 3.24-3.19$ and 3.14-3.09 (2m, 2H, $\left.\mathrm{CHCH}_{2} \mathrm{Ph}\right) .{ }^{13} \mathrm{C}$ NMR (101 MHz, DMSO) $\delta 182.7$ (CO-anthraquinone), 182.6 (CO-anthraquinone), $169.4(\mathrm{CHCOO}), 168.5(\mathrm{COCH}), 158.6\left(\mathrm{~F}_{3} \mathrm{CCO}, \mathrm{q},{ }^{2} J_{(\mathrm{C}-\mathrm{F})}=30 \mathrm{~Hz}\right), 142.1,135.2$, 135.1, 135.0, 134.1, 133.5, 133.5, 133.2, 129.8, 129.1, 127.8, 127.5, 127.3, $126.6($ Ar-C), 117.6 (q, $\left.C \mathrm{~F}_{3} \mathrm{CO},{ }^{1} J_{(\mathrm{C}-\mathrm{F})}=290 \mathrm{~Hz}\right)(\mathrm{Ar}-\mathrm{C}), 66.6\left(\mathrm{CH}_{2}\right.$-anthraquinone $), 53.7(\mathrm{CONHCH}), 36.6\left(\mathrm{CH}_{2} \mathrm{Ph}\right)$. Elemental analysis: $\mathrm{C}_{26} \mathrm{H}_{20} \mathrm{~F}_{3} \mathrm{NO}_{6}$ required $\mathrm{C}, 62.53 ; \mathrm{H}, 4.04 ; \mathrm{N}, 2.80$; found $\mathrm{C}, 62.48 ; \mathrm{H}, 4.04 ; \mathrm{N}, 2.78$. 


\subsection{CA Inhibition}

An Applied Photophysics stopped-flow instrument has been used for assaying the CA catalyzed $\mathrm{CO}_{2}$ hydration activity by using method of Khalifah. ${ }^{28,39}$ Phenol red (at a concentration of $0.2 \mathrm{mM}$ ) has been used as an indicator, working at the absorbance maximum of $557 \mathrm{~nm}$, with $20 \mathrm{mM}$ HEPES (pH 7.5) as buffer, and $20 \mathrm{mM} \mathrm{Na} 2 \mathrm{SO}_{4}$ (for maintaining constant the ionic strength), following the initial rates of the CA-catalyzed $\mathrm{CO}_{2}$ hydration reaction for a period of 10-100 s. The $\mathrm{CO}_{2}$ concentrations ranged from $1.7-17 \mathrm{mM}$ for the determination of the kinetic parameters and inhibition constants. For each inhibitor at least six traces of the initial 5\%-10\% of the reaction have been used for determining the initial velocity. The uncatalyzed rates were determined in the same manner and subtracted from the total observed rates. Stock solutions of inhibitor $(0.1 \mathrm{mM})$ were prepared in distilled-deionized water and dilutions up to $0.01 \mathrm{nM}$ were done thereafter with the assay buffer. Inhibitor and enzyme solutions were preincubated together for $15 \mathrm{~min}$ at room temperature prior to assay, in order to allow the formation of the E-I complex. The inhibition constants were obtained by non-linear least-square methods using PRISM (www.graphpad.com), and non-linear least squares methods, values representing the mean of at least three different determinations, as described earlier by us. ${ }^{40-45}$

\subsection{Antioxidant Activity}

\subsubsection{Radical Scavenging Activity Using DPPH method}

Antioxidant activity was determined based on the ability of the antioxidants to act as radical scavengers towards the stable free radical, 1,1-diphenyl-2-picrylhydrazyl (DPPH). As detailed by Yang, Guo, and Yuan (2008), ${ }^{29} 1 \mathrm{~mL}$ of antioxidant solution (solubilized in ethanol) was added to $3 \mathrm{~mL}$ of a $0.1 \mathrm{mM}$ ethanolic solution of DPPH. After $30 \mathrm{~min}$ at ambient temperature in darkness, absorbance readings were taken at $517 \mathrm{~nm}$. Inhibition (\%) was calculated using the equation

$$
[1-(\mathrm{As}-\mathrm{Ao}) / \mathrm{Ab}] \mathrm{x} 100
$$

whereby As was the absorbance reading for samples containing antioxidant, Ao was the absorbance of the antioxidant in pure ethanol and Ab corresponded to the absorbance of the DPPH solution.

\subsubsection{Ferric Ions Reducing Power Assay}

The reducing power of the compounds and standards was determined as described by Oyaizu. ${ }^{30}$ In brief, different concentrations of compounds $(5.88,14.70$ and $29.41 \mu \mathrm{g} / \mathrm{mL})$ in $1 \mathrm{~mL}$ ethanol were mixed with $2.5 \mathrm{~mL}$ of phosphate buffer $(0.2 \mathrm{M}, \mathrm{pH} 6.6)$ and $2.5 \mathrm{~mL}$ of $1 \%$ potassium ferricyanide and incubated at $50^{\circ} \mathrm{C}$ for $20 \mathrm{~min}$. At the end of the incubation, $2.5 \mathrm{~mL}$ of $10 \%$ trichloroacetic acid solution was added and centrifuged at $3000 \mathrm{rpm}$ for $10 \mathrm{~min}$. The upper layer of the solution $(2.5 \mathrm{~mL})$ was mixed with distilled water $(2.5 \mathrm{~mL})$ and $0.5 \mathrm{~mL}$ of $0.1 \%$ ferric chloride. The absorbance was measured at 700 $\mathrm{nm}$ against blank that contained distilled water and phosphate buffer. The reducing power tests were run in triplicate. Increase in absorbance of the reaction mixture indicated the reducing power of the samples/standards. $\alpha$-tocopherol, BHT or BHA was used as a positive control.

\subsubsection{Metal Chelating Activity}

Metal chelating activity was measured spectrophotometrically, by the method of Carter (1971). $3150 \mu \mathrm{L}$ of $2.0 \mathrm{mM} \mathrm{FeCl}_{2}$ is added to different concentrations of the compounds dissolved in ethanol. After $10 \mathrm{~min}$ of incubation at room temperature $\left(25^{\circ} \mathrm{C}\right), 200 \mu \mathrm{L}$ of $5.0 \mathrm{mM}$ ferrozine solution is added to this mixture. The mixture is again incubated for $25 \mathrm{~min}$ at room temperature $\left(25^{\circ} \mathrm{C}\right)$ and then the absorbance is measured at $562 \mathrm{~nm}$ using a spectrophotometer against blank $(3.75 \mathrm{~mL}$ ethanol, $50 \mu \mathrm{L}$ $\mathrm{FeCl}_{2}$ ). The solution of $3.75 \mathrm{~mL}$ ethanol, $50 \mu \mathrm{L} \mathrm{FeCl}$, and $200 \mu \mathrm{L}$ ferrozine is used as a control. Percentage of inhibition is calculated using the formula: 
Monopeptide-anthraquinone conjugates

Metal chelating activity $=\left(\mathrm{A}_{\text {control }}-\mathrm{A}_{\text {sample/standard }}\right) / \mathrm{A}_{\text {control }} \times 100$

Where $\mathrm{A}_{\text {control }}$ is the absorbance of control reaction (without analysed sample extract), and $\mathrm{A}_{\text {sample }} /$ $\mathrm{A}_{\text {standard }}$ is the absorbance of the analysed sample/standard. The values are presented as the mean of three measurements. Ethylenediaminetetraacetic acid (EDTA) was used as a positive control.

\section{Results and Discussion}

\subsection{Chemistry}

Anthraquinones, consisting of a tricyclic planar system, exhibit a wide range of important pharmaceutical and technological properties depending on their substituents. ${ }^{4}$ Despite their important pharmaceutical and technological properties, monopeptide-antraquinone derivatives have not been synthesized up to now. As far as we know, there are only a few reports about the synthesis of anthraquinone-containing peptide derivatives in the literatur. ${ }^{17,26,46}$ To fill this gap in the literature, we planned and synthesized a series of monopeptide-anthraquinone conjugates from the reaction of 2hydroxymethyl-anthraquinone with 1-(N-protected aminoacyl)benzotriazole in DMF (N,Ndimethylformamide) in the presence of $\mathrm{Et}_{3} \mathrm{~N}$. The synthesis of the N-protected monopeptideanthraquinone conjugates 1-16 is summarized in the Scheme 1. Kewmp and Reczek mentioned 2oxymethyleneanthraquinone (Maq) as a protecting group in peptide synthesis in their study, ${ }^{47}$ although they shared information about compound 1, but since it appeared as new in the SciFinder database search, all information about this compound is included in this article.

All the synthesized monopeptide-anthraquinone conjugates were crystalline solids, air stable and had sharp melting points. The structures of $\mathrm{N}$-protected monopeptide-anthraquinone conjugates (116) were elucidated by ${ }^{1} \mathrm{H}$ NMR, ${ }^{13} \mathrm{C}$ NMR, IR, mass and elemental analyses. While the characteristic methylene resonances of the 2-hydroxymethylanthraquinone moiety of the monopeptide-anthraquinone derivatives for compounds 1-3, 7, 9, 13-16 were observed at 5.29-5.36 ppm region as singlet peak, for compounds 4-6, 8, 10-12 were observed as multiplet due to chiral neighboring effects of the asymmetric carbons of the amino acids in the ${ }^{1} \mathrm{H}$ NMR spectra. Similar peak splitting was observed for the methylene peak of the benzyloxycarbonyl-protecting group of compounds $\mathbf{3}, \mathbf{4}, \mathbf{5}, \mathbf{6}$ and 7. For compound 1, the NH proton signal was observed at $7.82 \mathrm{ppm}$ as the triplet peak, while those of compounds $3, \mathbf{6}$, and $\mathbf{9}$ were observed as a doublet peaks in the range of 7.78-7.87 ppm as expected in the ${ }^{1} \mathrm{H}$ NMR spectra. All other NH peaks resonated with some aromatic protons in the region of 7.97$7.80 \mathrm{ppm}$, while that of compound $\mathbf{1 5}$ was observed as a large single peak at $7.93 \mathrm{ppm}$. In Compound 9, the single peak of the tert-butoxy group of about $1.33 \mathrm{ppm}$ was disappeared in compounds $\mathbf{1 6}$ where the Boc protecting group was removed.

Similarly, the quaternary carbon peak around 78,9 ppm and the carbamate carbonyl peak around $155.9 \mathrm{ppm}$ seen in the ${ }^{13} \mathrm{C}$ NMR spectra of the compounds 9 disappeared in compounds 16. After removing the Boc protecting group, the free amino group formed was converted to trifluoroacetate salt by taking a proton from TFA. This was confirmed by a broad singlet peak corresponding to 3 protons at $8.65 \mathrm{ppm}$ in the proton NMR spectra of compounds $\mathbf{1 6}$ and their element analysis result. Similar results were obatined in our previous study ${ }^{[27]}$. In compounds 16, carbon peaks belonging to the trifluoroacetate group were seen as quartet in the carbon 13 spectra at around 158 and $117 \mathrm{ppm}$. All NH protons were confirmed by deuterium exchange by $\mathrm{D}_{2} \mathrm{O}$. Carbonyl resonances of the anthraquinone moiety for monopeptide-anthraquinone conjugates were observed around 182.8-182.5 ppm. Carbonyl resonances of the ester carbonyl and carbamate carbonyl for monopeptide-anthraquinone conjugates were observed around 174.4-170.6 and 157.1-155.8 ppm, respectively. All other aliphatic and aromatic protons and carbons peaks of monopeptide-antarquinone conjugates are seen in the expected places and confirm the proposed structures, as can be seen from the spectra given in the supporting information files, which are not explained here individually. IR spectra of mono peptide-anthraquinone conjugates, 1-15, showed characteristic ester, ketone and carbamate carbonyl peaks around between $1749-1722 \mathrm{~cm}^{-}$ ${ }^{1}, 1711-1682 \mathrm{~cm}^{-1}, 1684-1613 \mathrm{~cm}^{-1}$, respectively. While no peak of carbamate carbonyl was observed in the IR spectrum of compound 16, other carbonyls were seen at 1745, 1672 and $1645 \mathrm{~cm}^{-1}$. While NH 
vibrations were observed between $3374-3314 \mathrm{~cm}^{-1}$ in the IR spectra of compounds $\mathbf{1 - 1 5}$, this peak was observed at $3159 \mathrm{~cm}^{-1} \mathrm{ppm}$ in compound 16 as $\mathrm{NH}_{3}$. When the mass spectra of the compounds (1-15) were examined, fragmentation compatible with the targeted structures and molecular ion peaks were clearly observed.

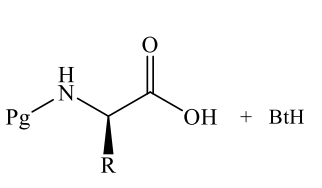

Pg: Protecting group Z: Benzyloxycarbonyl Boc:tert-Butyloxycarbonyl Fmoc: Fluorenylmethyloxycarbonyl BtH: Benzotriazole

1) R: H, Pg: Z

2) R: $\mathrm{CH}_{3}, \mathrm{Pg}: \mathrm{Z}$

3) $\mathrm{R}: \mathrm{CH}_{2} \mathrm{Ph}, \mathrm{Pg}: \mathrm{Z}$

4) $\mathrm{R}: \mathrm{CH}\left(\mathrm{CH}_{3}\right)_{2}, \mathrm{Pg}: \mathrm{Z}$

5) R: $\mathrm{CH}_{2} \mathrm{CH}\left(\mathrm{CH}_{3}\right)_{2}, \mathrm{Pg}: \mathrm{Z}$

6) $\mathrm{R}: \mathrm{CH}_{2} \mathrm{CH}_{2} \mathrm{SCH}_{3}, \mathrm{Pg}: \mathrm{Z}$

7) $\mathrm{R}: \mathrm{CH}_{2}$ (3-indoyll), $\mathrm{Pg}: \mathrm{Z}$

8) $\mathrm{R}: \mathrm{CH}_{3}, \mathrm{Pg}: \mathrm{Boc}$

9) $\mathrm{R}: \mathrm{CH}_{2} \mathrm{Ph}, \mathrm{Pg}$ : $\mathrm{Boc}$

10) R: $\mathrm{CH}\left(\mathrm{CH}_{3}\right)_{2}, \mathrm{Pg}$ : Boc

11) $\mathrm{R}: \mathrm{CH}\left(\mathrm{CH}_{3}\right) \mathrm{CH}_{2} \mathrm{CH}_{3}, \mathrm{Pg}$ : Boc

12) $\mathrm{R}: \mathrm{CH}_{2} \mathrm{CH}_{2} \mathrm{SCH}_{3}$, $\mathrm{Pg}$ : Boc

13) R: $\mathrm{CH}_{2}$ (3-indolyl), $\mathrm{Pg}$ : Boc

14) R: H, Pg: Fmoc

15) R: $\mathrm{CH}_{2} \mathrm{Ph}, \mathrm{Pg}$ : Fmoc<smiles>[R]C(NC)C(=O)n1nnc2ccccc21</smiles>

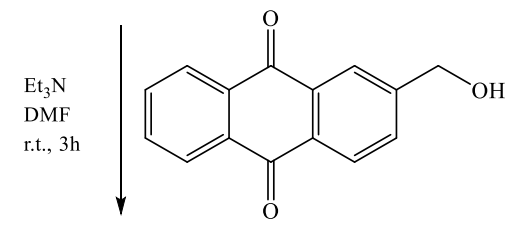

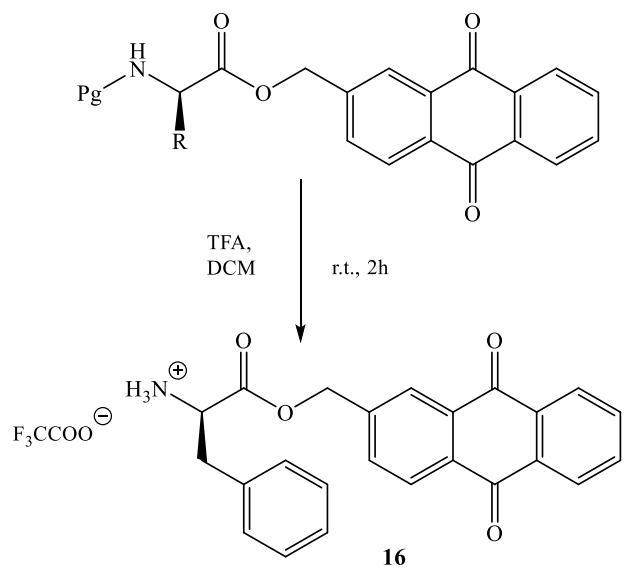

Scheme 1. Synthetic pathways of N-protected monopeptide-anthraquinone conjugates, 1-16

\subsection{Carbonic Anhydrase Inhibition}

All the synthesized monopeptide-anthraquinone conjugates have been evaluated by means of a stopped flow $\mathrm{CO}_{2}$ hydrase assa ${ }^{28}$ to test their inhibitory potency against four human (h) CA isoforms (hCA I and hCA II). Inhibition data are reported in Table 1, along with those referred to acetazolamide (AAZ), used as standard sulfonamide inhibitor. As seen in Table 1, none of the compounds showed inhibition below Ki $100 \mu \mathrm{M}$ concentrations against hCA I enzyme. However, compounds 7, $\mathbf{1 3}$ and $\mathbf{1 5}$ showed considerable inhibition against CA II with Ki values in the low $\mu \mathrm{M}$ levels 43.5, 78.2 and 67.4, respectively. When the structures of compounds effective against hCA II are examined, it is understood that compounds $\mathbf{7}$ and 13, which contain a tryptophan amino acid moiety, play an important role in inhibition. The inhibition effect in compound $\mathbf{1 5}$ that shows inhibition by Ki $67.4 \mathrm{M}$ against hCA II is thought to be effective together with the phenylalanine and Fmoc (fluorenylmethyloxycarbonyl) group. In order to see the effect of amino acid protecting group in monopeptide-anthraquinone conjugates on CA I and CA II enzyme inhibitions, the protecting group of compound 9 was removed. When the CA I and CA II enzyme inhibition results of the deprotected compound 16 were compared with the compound 9, there was no change in the CA I and CA II enzyme inhibition results. 
Monopeptide-anthraquinone conjugates

Table 1. Inhibition data of hCA I and hCA II, with compounds 1-16 and the standard sulfonamide inhibitor acetazolamide (AAZ) by a stopped flow $\mathrm{CO}_{2}$ hydrase assay

\begin{tabular}{ccc}
\hline & \multicolumn{2}{c}{$\mathbf{K}_{\mathbf{I}}(\boldsymbol{\mu M})^{*}$} \\
\hline Compound & hCA I & hCA II \\
$\mathbf{1}$ & $>100$ & $>100$ \\
$\mathbf{2}$ & $>100$ & $>100$ \\
$\mathbf{3}$ & $>100$ & $>100$ \\
$\mathbf{4}$ & $>100$ & $>100$ \\
$\mathbf{5}$ & $>100$ & $>100$ \\
$\mathbf{6}$ & $>100$ & $>100$ \\
$\mathbf{7}$ & $>100$ & 43.5 \\
$\mathbf{8}$ & $>100$ & $>100$ \\
$\mathbf{9}$ & $>100$ & $>100$ \\
$\mathbf{1 0}$ & $>100$ & $>100$ \\
$\mathbf{1 1}$ & $>100$ & $>100$ \\
$\mathbf{1 2}$ & $>100$ & $>100$ \\
$\mathbf{1 3}$ & $>100$ & 78.2 \\
$\mathbf{1 4}$ & $>100$ & $>100$ \\
$\mathbf{1 5}$ & $>100$ & 67.4 \\
$\mathbf{1 6}$ & $>100$ & $>100$ \\
$\mathbf{A A Z}$ & 0.25 & 0.012 \\
\hline
\end{tabular}

* Mean from 3 different assays, by a stopped flow technique (errors were in the range of $\pm 5-10 \%$ of the reported values).

\subsection{Antioxidant Activity}

\subsubsection{DPPH Radical Scavenging Activity}

The antioxidant activities of the monopeptide-anthraquinone conjugates were determined by considering the radical scavenging capacity of the antioxidants against the stable free radical, 1,1diphenyl-2-picrylhydrazil (DPPH). ${ }^{29}$ Antioxidant testing results are reported in Table 2, along with those referred to BHA, BHT and $\alpha$-tocopherol, commonly used as standard antioxidants. When the antioxidant activities of the compounds were examined, it was seen that the compounds showing the best antioxidant activity were in the tryptophan (compounds 7 and 13), methionine (compounds 6 and 12) and valine (compounds 4 and 10) amino acids and anthraquinone conjugates. When the obtained antioxidant activities are evaluated in terms of protecting groups in monopeptide-anthraquinone conjugates, it can be said that in general, Fmoc (compound 15) and Boc (compound 8-13) protecting groups contribute more to antioxidant activity compared to $\mathrm{Z}$ (compounds 1-7). In order to see the effect of amino acid protecting group in monopeptide-anthraquinone conjugates on antioxidant activity, the protecting group of compound 9 was removed. When the antioxidant results of compound 16, obtained by removing the protecting group, were compared with compound 9, a significant increase was observed in the antioxidant properties of compound $\mathbf{1 6}$. In our previous study, we reached a similar conclusion regarding antioxidant activity. ${ }^{48}$ 
Küçükbay et al., Org. Commun. (2021) 14:3 255-269

Table 2. Antioxidant activities of the synthesized monopeptide-athraquinone derivatives according to radical Scavenging method

\begin{tabular}{cccccc}
\hline \multirow{2}{*}{ Compound } & \multicolumn{6}{c}{ DPPH Free Radical Scavenging Activity, \%* } \\
\cline { 2 - 6 } & $\mathbf{1 2 . 5}$ & $\mathbf{2 5}$ & $\mathbf{3 7 . 5}$ & $\mathbf{6 2 . 5}$ & $\mathbf{1 2 5}$ \\
& $\boldsymbol{\mu M}$ & $\boldsymbol{\mu M}$ & $\boldsymbol{\mu M}$ & $\boldsymbol{\mu M}$ & $\boldsymbol{\mu M}$ \\
\hline $\mathbf{1}$ & 3.908 & 6.255 & 9.382 & 9.382 & 9.382 \\
$\mathbf{2}$ & 3.785 & 2.270 & 4.543 & 5.299 & 4.453 \\
$\mathbf{3}$ & 4.303 & 6.660 & 8.525 & 11.444 & 12.849 \\
$\mathbf{4}$ & 9.231 & 13.818 & 13.335 & 19.828 & 32.124 \\
$\mathbf{5}$ & 8.168 & 9.627 & 10.332 & 12.084 & 13.186 \\
$\mathbf{6}$ & 2.677 & 14.673 & 27.346 & 27.307 & 37.285 \\
$\mathbf{7}$ & 15.408 & 20.476 & 30.599 & 39.341 & 45.962 \\
$\mathbf{8}$ & 13.133 & 14.748 & 15.626 & 17.190 & 22.656 \\
$\mathbf{9}$ & 6.915 & 8.135 & 8.996 & 14.022 & 14.204 \\
$\mathbf{1 0}$ & 13.050 & 15.353 & 19.176 & 26.822 & 39.904 \\
$\mathbf{1 1}$ & 9.668 & 10.844 & 11.824 & 15.616 & 26.773 \\
$\mathbf{1 2}$ & 13.587 & 17.163 & 19.309 & 27.835 & 36.402 \\
$\mathbf{1 3}$ & 17.284 & 26.885 & 32.608 & 42.249 & 55.668 \\
$\mathbf{1 4}$ & 3.242 & 3.654 & 3.674 & 3.890 & 4.126 \\
$\mathbf{1 5}$ & 8.289 & 16.579 & 18.236 & 26.527 & 36.474 \\
$\mathbf{1 6}$ & 8.795 & 10.133 & 13.193 & 26.575 & 37.151 \\
$\mathbf{B H A}$ & 86.233 & 86.221 & 86.222 & 88.145 & 88.114 \\
$\mathbf{B H T}$ & 65.657 & 73.869 & 75.654 & 75.987 & 78.181 \\
$\boldsymbol{\alpha}$-Tocopherol & 87.242 & 88.343 & 89.125 & 90.343 & 90.357 \\
\hline
\end{tabular}

$* \overline{\text { Mean from } 3 \text { different assays (errors were in the range of } \pm 0.3-1.0 \% \text { of the reported values) }}$

\subsubsection{Ferric Ions Reducing Power Assay}

Antioxidant results of the ferric ion reducing power of the compounds are given in Table 3 together with the standard antioxidants BHA, BHT and alpha tocopherol. When the values in Table 3 were compared with the antioxidant values of the standard compounds, it was determined that monopeptide-anthraquinone conjugates had weak antioxidant capacity. Although weak, compounds 7 and $\mathbf{1 3}$ containing tryptophan amino acid, $\mathbf{1 1}$ compounds containing isoleucine amino acid and $\mathbf{1 6}$ compounds containing phenylalanine amino acid from which the protecting group was removed showed the best antioxidant activity.

\subsubsection{Metal Chelating Activity}

None of the compounds showed antioxidant activity according to the metal chelation method made according to the Carter method. 
Monopeptide-anthraquinone conjugates

Table 3. Antioxidant activities of the synthesized monopeptide-athraquinone derivatives according to ferric ions reducing power

\begin{tabular}{rccc}
\hline Compound & \multicolumn{3}{c}{ Ferric ions reducing power (Absorbance, $\mathbf{7 0 0} \mathbf{~ n m}$ ) } \\
\cline { 2 - 4 } & $\mathbf{5 . 8 8} \boldsymbol{\mu \mathbf { g } / \mathbf { m L }}$ & $\mathbf{1 4 . 7 0} \boldsymbol{\mu g} / \mathbf{m L}$ & $\mathbf{2 9 . 4 1} \boldsymbol{\mu g} / \mathbf{m L}$ \\
\hline $\mathbf{1}$ & 0.094 & 0.104 & 0.114 \\
$\mathbf{2}$ & 0.081 & 0.093 & 0.097 \\
$\mathbf{3}$ & 0.094 & 0.097 & 0.111 \\
$\mathbf{4}$ & 0.094 & 0.099 & 0.107 \\
$\mathbf{5}$ & 0.096 & 0.095 & 0.095 \\
$\mathbf{6}$ & 0.070 & 0.075 & 0.091 \\
$\mathbf{7}$ & 0.069 & 0.091 & 0.141 \\
$\mathbf{8}$ & 0.094 & 0.096 & 0.098 \\
$\mathbf{9}$ & 0.076 & 0.079 & 0.094 \\
$\mathbf{1 0}$ & 0.073 & 0.097 & 0.105 \\
$\mathbf{1 1}$ & 0.095 & 0.114 & 0.161 \\
$\mathbf{1 2}$ & 0.090 & 0.094 & 0.114 \\
$\mathbf{1 3}$ & 0.085 & 0.097 & 0.156 \\
$\mathbf{1 4}$ & 0.093 & 0.095 & 0.116 \\
$\mathbf{1 5}$ & 0.079 & 0.090 & 0.095 \\
$\mathbf{1 6}$ & 0.094 & 0.095 & 0.124 \\
BHA & 0.464 & 1.296 & 1.827 \\
$\mathbf{B H T}$ & 0.257 & 0.491 & 0.844 \\
$\boldsymbol{\alpha}-\mathbf{T o c o p h e r o l}$ & 0.220 & 0.456 & 0.779 \\
\hline
\end{tabular}

\section{Conclusion}

In conclusion, we prepared sixteen new ester-structured monopeptide-anthraquinone conjugates using the benzotriazole methodology. To prepare these compounds, first the carbonyl carbon of the amino acid with the protecting group was activated with benzotriazole, an easily leaving group, and then esterified with 2-hydroxymethylanthraquinone. Human carbonic anhydrase hCA I and hCA II enzyme inhibition and antioxidant capacities of the compound were evaluated by the stopped-flow and DPPH methods, respectively. However, only three compounds (7, 13 and 15) showed some inhibition properties against hCA II enzymes and none of the compounds showed inhibitory properties against hCA I enzyme. The antioxidant capacities of the compounds were determined by DPPH, ferric ion reducing assay and metal chelation methods. When the antioxidant capacities of the compounds were compared with the results of the standard antioxidants BHA, BHT and $\alpha$-tocopherol, a small amount of antioxidant activity was observed according to the DPPH and ferric ion reducing power test methods, while none of the compounds showed antioxidant properties according to the metal chelating activity method using ethylenediaminetetracetic acid as a standard at the concentrations studied.

\section{Disclosure statement}

The author(s) confirm that this article content has no conflict of interest.

\section{Acknowledgements}

This work was financially supported by the İnönü University Research Fund (FYL-2019-1634). 
Küçükbay et al., Org. Commun. (2021) 14:3 255-269

\section{Supporting Information}

Supporting information accompanies this paper on http://www.acgpubs.org/journal/organic$\underline{\text { communications }}$

\section{ORCID}

Hasan Küçükbay: 0000-0002-7180-9486

Fatma Müzeyyen Parladı: 0000-0003-1486-4873

F. Zehra Küçükbay: 0000-0002-5471-3933

Andrea Angeli: 0000-0002-1470-7192

Gianluca Bartolucci: 0000-0002-5631-8769

Claudiu T. Supuran: $\underline{0000-0003-4262-0323}$

\section{References}

[1] Park, J.; Park, S.; Park, J. Synthesis of new dye compounds based on anthraquinone moiety for color filter colorants. Mol. Cryst. Liq. Cryst. 2013, 579, 110-114.

[2] Kaim, W.; Lahiri, G.K. The coordination potential of indigo, anthraquinone and related redox-active dyes. Coord. Chem. Rev. 2019, 393, 1-8.

[3] Langdon-Jones, E.E.; Pope, S.J.A. The coordination chemistry of substituted anthraquinones: Developments and applications. Coord. Chem. Rev. 2014, 269, 32-53.

[4] Peixoto, D.; Figueiredo, M.; Malta, G.; Roma-Rodrigues, C.; Baptista, P.V.; Fernandes, A.R.; Barroso, S.; Carvalho, A.L.; Afonso, C.A.M.; Ferreira, L.M.; Paula S. Branco, P.S. Synthesis, cytotoxicity evaluation in human cell lines and in vitro DNA interaction of a hetero-arylidene-9(10H)-anthrone. Eur. J. Org. Chem. 2018, 545-549.

[5] Dibble, D.; Kurakake, R.; Wardrip, A.G.; Bartlett, A.; Lopez, R.; Linares, J.A.; Firstman, M.; Schmidt, A.M.; Umerani, M.J.; Gorodetsky, A.A. Aza-Diels-Alder approach to diquinolineanthracene and polydiquinolineanthracene derivatives. Org. Lett. 2018, 20, 502-505.

[6] Qiao, M.; Liu, B.; Zhao, X.; Gong, Y.; Wang, Y.; Cao, W. Formation of oxygenated polycyclic aromatic hydrocarbons by photoelectrocatalysis using $\mathrm{TiO}_{2}$ nanotubes. RSC Adv. 2017, 7, 51678-51686.

[7] Bardagi, J.I.; Ghosh, I.; Schmalzbauer, M.; Ghosh, T.; König, B. Anthraquinones as photoredox catalysts for the reductive activation of aryl halides. Eur. J. Org. Chem. 2018, 34-40.

[8] Bartels, P.L.; Stodola, J.L.; Burgers, P.M.J.; Barton, J.K. A redox role for the [4Fe 4 S] cluster of yeast DNA polymerase $\delta$. J. Am. Chem. Soc. 2017, 139, 18339-18348.

[9] Inagawa, H.; Uchida, S.; Yamaguchi, E.; Itoh, A. Metal-free oxidative amidation of aromatic aldehydes using an anthraquinone-based organophotocatalyst. Asian J. Org. Chem. 2019, 8, 1411-1414.

[10] Petroselli, M.; Mosca, S.; Martí-Rujas, J.; Comelli.; Cametti, M. Mixed stacked charge-transfer $\pi$-organic materials based on anthracenyl boronic acid. Eur. J. Org. Chem. 2017, 7190-7194.

[11] Hussein, Y.H.A.; Anderson, N.; Lian, T.T.; Abdou, I.M.; Strekowski, L.; Timoshchuk, V.A.; Vaghefi, M.M.; Thomas L. Netzel, T.L. Solvent and linker influences on AQ .--/dA .+ charge-transfer state energetics and dynamics in anthraquinonyl-linker-deoxyadenosine conjugates. J. Phys. Chem. A 2006, 110, 4320-8.

[12] Khankaew, S.; Mills, A.; Yusufu, D.; Wellsb, N.; Hodgenb, S.; Boonsupthipc, W.; Suppakula, P. Multifunctional anthraquinone-based sensors: UV, $\mathrm{O}_{2}$ and time. Sensors Actuators B. Chem. 2017, 238, $76-82$.

[13] Liu, W.; Dong, H.; Zhang, L.; Tian, Y. Development of an efficient biosensor for the In vivo monitoring of $\mathrm{Cu}+$ and $\mathrm{pH}$ in the brain: Rational design and synthesis of recognition molecules. Angew. Chem. Int. Ed. 2017, 56, 16328-16332.

[14] Xiang, W.; Song, Q.S.; Zhang, H.J.; Guo, S.P. Antimicrobial anthraquinones from Morinda angustifolia. Fitoterapia 2008, 79, 501-504.

[15] Bringmann, G.; Mutanyatta-Comar, J.; Maksimenka, K.; Wanjohi, J.M.; Heydenreich, M.; Brun, R.; Müller, W.E.G.; Peter, M.G.; Jacob O. Midiwo, J.O.; Yenesew, A. Joziknipholones A and B: The first dimeric phenylanthraquinones, from the roots of Bulbine frutescens. Chem. A Eur. J. 2008, 14, 14201429. 


\section{Monopeptide-anthraquinone conjugates}

[16] Mishra, S.K.; Tiwari, S.; Shrivastava, A.; Srivastava, S.; Boudh, G.K.; Chourasia , S.K.; Chaturvedi, U.; Mir, S.S.; Saxena, A.K.; Bhatia, G.; Lakshmi, V. Antidyslipidemic effect and antioxidant activity of anthraquinone derivatives from Rheum emodi rhizomes in dyslipidemic rats. J. Nat. Med. 2014, 68, 363-371.

[17] Hsin, L.W.; Wang, H.P.; Kao, P.H.; Lee, O.; Chen, W.R.; Chen, H.W.; Guh, J.H.; Chan, Y.L.; His, C.P.; Yang, M.S.; Tsai-Kun Lic, .K.; Lee, C.H. Synthesis, DNA binding, and cytotoxicity of 1,4- bis(2-aminoethylamino)anthraquinone-amino acid conjugates. Bioorg. Med. Chem. 2008, 16, 1006-1014.

[18] Yan, Y.; Su, X.; Liang, Y.; Zhang, J.; Shi, C.; Lu, Y.; Gu, L.; Fu, L. Emodin azide methyl anthraquinone derivative triggers mitochondrial- dependent cell apoptosis involving in caspase-8-mediated Bid cleavage. Mol. Cancer. Ther. 2008, 7, 1688-1697.

[19] Lee, Y.K.; Bang, H.; Oh, J.B.; Whang, W.K. Bioassay-guided isolated compounds from morinda officinalis inhibit Alzheimer's disease pathologies. Molecules 2017, 22, Article number 1638, 1-12.

[20] Seo, E. J.; Ngoc, T. M.; Lee, S. M.; Kim, Y. S.; Jung, Y. S. Chrysophanol-8-O-glucoside, an anthraquinone derivative in rhubarb, has antiplatelet and anticoagulant activities. J. Pharmacol. Sci. 2012, $118,245-54$..

[21] Barnard, D.L.; Huffman, J. H.; Morris, J.L.B.; Wood, S.G.; Hughes, B.G.; Sidwell, R. W. Evaluation of the antiviral activity of anthraquinones, anthrones and anthraquinone derivatives against human cytomegalovirus. Antiviral Res. 1992, 17, 63-77.

[22] Campora, M.; Francesconi, V.; Schenone, S.; Tasso, B.; Tonelli, M. Journey on naphthoquinone and anthraquinone derivatives: New insights in alzheimer's disease. Pharmaceuticals. 2021, 14, 1-33..

[23] Routier, S.; Cotelle, N.; Catteau, J. P.; Bernier, J. L.; Waring, M.J.; Riou, J.F.; Bailly, C. Salenanthraquinone conjugates. Synthesis, DNA-binding and cleaving properties, effects on topoisomerases and cytotoxicity. Bioorg. Med. Chem. 1996, 4, 1185-96.

[24] Evans, L.W.; Bender, A.; Burnett, L.; Godoy, L.; Shen, Y.; Staten, D.; Zhou, T.; Angermann, J.E.; Ferguson, B.S. Emodin and emodin-rich rhubarb inhibits histone deacetylase (HDAC) activity and cardiac myocyte hypertrophy. J. Nutr. Biochem. 2020, 79, Article Number: 108339.

[25] Luo, M.; Cui, Z.; Huang, H.; Song, X.; Sun, A.; Dang, Y.; Lu, L.; JJu, J. Amino acid conjugated anthraquinones from the marine-derived fungus penicillium sp. SCSIO sof101. J. Nat. Prod. 2017, 80, 1668-1673.

[26] Zagotto, G.; Sissi, C.; Lucatello, L.; Pivetta, C.; Cadamuro, S.A.; Fox, K.R.; Neidle, S.; Palumbo, M. Aminoacyl-anthraquinone conjugates as telomerase inhibitors: Synthesis, biophysical and biological evaluation. J. Med. Chem. 2008, 51, 5566-5574.

[27] Yuan, C.; He, Q.; Song, S.; Zhang, X.; Miao, Z.; Yang, C. One Pot and Metal-Free Approach to 3-(2Hydroxybenzoyl)-1-aza- anthraquinones. Molecules 2019, 24, Article Number: 3017.

[28] Khalifah, R.G. The Carbon dioxide hydration activity of carbonic anhydrase. J. Biol. Chem. 1971, 246(8), 2561-2573.

[29] Yang, J.; Guo, J.; Yuan, J. In vitro antioxidant properties of rutin. LWT - Food Sci. Technol. 2008, 41, 1060-1066.

[30] Oyaizu, M. Studies on products of browning reaction. Antioxidative activities of products of browning reaction prepared from glucosamine. Japanese J. Nutr. Diet. 1986, 44, 307-315.

[31] Carter, P. Spectrophotometric determination of serum iron at the submicrogram level with a new reagent (ferrozine). Anal. Biochem. 1971, 40, 450-458.

[32] El-Khatib, M.; Jauregui, L.; Tala, S.R.; Khelashvili, L.; Katritzky, A.R. Solution-phase synthesis of chiral O-acyl isodipeptides. Medchemcomm. 2011, 2, 1087-1092.

[33] Küçükbay, F.Z.; Küçükbay, H.; Tanc, M.; Supuran, C.T. Synthesis and carbonic anhydrase inhibitory properties of amino acid-coumarin/quinolinone conjugates incorporating glycine, alanine and phenylalanine moieties. J. Enzyme. Inhib. Med. Chem. 2016, 31, 198-202.

[34] Küçükbay, F.Z.; Küçükbay, H.; Tanc, M.; Supuran, C.T. Synthesis and carbonic anhydrase I, II, IV and XII inhibitory properties of N- protected amino acid - sulfonamide conjugates. J. Enzyme Inhib. Med. Chem. 2016, 31, 1476-1483.

[35] Buğday, N.; Küçükbay, F.Z.; Apohan, E.; Küçükbay, H.; Serindağ, A.; Yeşilada, Ö. Synthesis and evaluation of novel benzimidazole conjugates incorporating amino acids and dipeptide moieties. Lett. Org. Chem. 2017, 14, 198-206.

[36] Küçükbay, H.; Buğday, N.; Küçükbay, F. Z.; Berrino, E.; Bartolucci, G.; Prete, S.D.; Capasso, C.; Supuran.; C.T. Synthesis and carbonic anhydrase inhibitory properties of novel 4-(2aminoethyl)benzenesulfonamide-dipeptide conjugates. Bioorg. Chem. 2019, 83, 414-423.

[37] Katritzky, A .R.; Singh, S. A.; Haase, D. N.; Yoshioka, M. N-(Fmoc- $\alpha$-aminoacyl)benzotriazoles: versatile synthetic reagents from proteinogenic amino acids. Arkivoc 2009, (viii), 47-56.

[38] Merrifield, B. Solid phase synthesis. Science 1986, 232, 341-347.

[39] Khalifah, R. G. Edsall, J. Carbon dioxide hydration activity of carbonic anhydrase: kinetics of alkylated 
Küçükbay et al., Org. Commun. (2021) 14:3 255-269

anhydrases B and C from humans (metalloenzymes-isoenzymes-active sites-mechanism). Proc. Natl. Acad. Sci. USA 1972, 69, 172-176.

[40] Mincione, F.; Starnotti, M.; Menabuoni, L.; Scozzafava, A.; Casini, A.; Supuran, C.T. arbonic anhydrase inhibitors: 4-Sulfamoyl-benzenecarboxamides and 4-chloro-3-sulfamoyl-benzenecarboxamides with strong topical antiglaucoma properties. Bioorg. Med. Chem. Lett. 2001, 11, 1787-1791.

[41] Prete, S. D.; Vullo, D.; Luca, D. V.; AlOthman, Z.; Osman, S .M.; Supuran, C. T.; Capasso, C.. Biochemical characterization of recombinant $\beta$-carbonic anhydrase (PgiCAb) identified in the genome of the oral pathogenic bacterium Porphyromonas gingivalis. J. Enzyme Inhib. Med. Chem. 2015, 30, 366370 .

[42] Supuran, C. T.; Scozzafava, A. Carbonic anhydrases as targets for medicinal chemistry. Bioorg. Med. Chem. 2007, 15, 4336-4350.

[43] Maresca, A.; Vullo, D.; Scozzafava, A.; Manole, G.; Supuran, C. T. Inhibition of the $\beta$-class carbonic anhydrases from Mycobacterium tuberculosis with carboxylic acids. J. Enzyme Inhib. Med. Chem. 2014, 28, 392-396.

[44] Scozzafava, A.; Passaponti, M.; Supuran, C. T.; Gülçin, I. Carbonic anhydrase inhibitors: Guaiacol and catechol derivatives effectively inhibit certain human carbonic anhydrase isoenzymes (hCA I, II, IX and XII). J. Enzyme Inhib. Med. Chem. 2015, 30, 586-591.

[45] Küçükbay, H.; Buğday, N.; Küçükbay, F. Z.; Angeli, A.; Bartolucci, G.; Supuran, C. T.;Synthesis and human carbonic anhydrase I, II, VA, and XII inhibition with novel amino acid-sulphonamide conjugates J. Enzyme Inhib. Med. Chem. 2020, 35, 489-497.

[46] Bogdanowicz, R.; Sawczak, M.; Niedzialkowski, P.; Zieba, P.; Finke, B.; Ryl, J.; Ossowski, T. Direct amination of boron-doped diamond by plasma polymerized allylamine film. Phys. Status Solidi A. 2014, $211,2319-327$

[47] Kemp, D. S.; Reczek, J. New protective groups for peptide synthesis--III the maq ester group mild reductive cleavage of 2-acyloxymethyleneanthraquinones. Tetrahedron Lett. 1977, 18, 1031-1034.

[48] Küçükbay, H.; Gönül, Z.; Küçükbay, F. Z.; Tekin, Z.; Angeli, A.; Bartolucci, G.; Supuran, C. T.; Tatlıc1, E.; Apohan, E.; Yeşilada, Ö. Synthesis of new 7-amino-3,4-dihydroquinolin-2(1H)-one-peptide derivatives and their carbonic anhydrase enzyme inhibition, antioxidant and cytotoxic activities. Arch. Pharm. (Weinheim). 2021, (July), Article Number: e2100122.

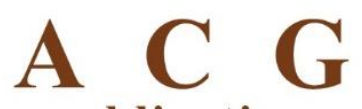

publications

(C) 2021 ACG Publications 